\title{
Non-Autogenous Innovative Reconstruction Method Following Mandibulectomy
}

\author{
Bahaa Haj Yahya ${ }^{1}$, Eli Rosenfeld ${ }^{1}{ }^{(D}$, Gavriel Chaushu ${ }^{2}{ }^{\circ}$, Ilana Kaplan ${ }^{3}$, Yehonantan Ben-Zvi ${ }^{1}$ \\ and Yafit Hamzani ${ }^{1, *}$ \\ 1 Department of Oral and Maxillofacial Surgery, Rabin Medical Center-Beilinson Hospital, \\ Petach Tikva 4941492, Israel; yafitha@clalit.org.il (B.H.Y.); eliros@gmail.com (E.R.); \\ yonident@gmail.com (Y.B.-Z.) \\ 2 Department of Oral and Maxillofacial Surgery, The Maurice and Gabriela Goldschleger School of Dental \\ Medicine, Tel Aviv University, Tel Aviv; Head, Department of Oral and Maxillofacial Surgery, \\ Rabin Medical Center-Beilinson Hospital, Petach Tikva 4941492, Israel; gabi.chaushu@gmail.com \\ 3 Department of Oral Pathology, Rabin Medical Center-Beilinson Hospital, Petach Tikva 4941492, Israel; \\ Dr.ilanakaplan@gmail.com \\ * Correspondence: yafithm87@gmail.com; Tel.: +972-3-9377207; Fax: +972-3-9377204
}

Received: 15 June 2020; Accepted: 24 June 2020; Published: 30 June 2020

\begin{abstract}
Plexiform ameloblastoma is a locally aggressive odontogenic tumor, rare in the anterior mandible. The treatment of choice is resection with $1-3 \mathrm{~cm}$ free margins. In most of reported cases, the affected mandible is reconstructed by autogenic bone graft or osseocutaneous microvascular free flap in order to return function and esthetics. Case description: A $2 \mathrm{~cm}$ diameter exophytic ameloblastoma, located in the anterior mandible of a 50-year-old male was resected and reconstructed in a unique manner-allogenic bone block, recombinant human bone morphogenetic protein (rhBMP) and xenograft particles via transcutaneous submental approach. After bone maturation, dental implants were placed and restored by fixed prosthetics. Practical implications: Mandible reconstruction modalities have a crucial influence on patient quality of life, function and esthetics. Allogenic bone block combined with rhBMP and xenograft particles can replace the traditional autogenous bone in certain circumstances. A submental transcutaneous "tent pole" approach can improve the success rate of the reconstruction procedure.
\end{abstract}

Keywords: ameloblastoma; mandible; bone block; allogenic; autogenic; rhBMP

\section{Introduction}

Ameloblastoma, a benign tumor of odontogenic epithelial origin, occurs in $0.78 \%$ of oral cavity neoplasia [1,2]. For the plexiform type, radical resection with a safety margins of $1 \mathrm{~cm}$ to $3 \mathrm{~cm}$ is recommended [1,3]. Resection in the mandible can lead to either marginal or segmental mandibulectomy defects. Marginal mandibulectomy defects involve the resection of a single cortex of the mandible and can be restored in different ways, such as osseocutaneous microvascular free flaps or non-vascularized bone grafts. The most popular among the former is fibula due to its long pedicle, ease of contouring with multiple osteotomies, and suitability as a recipient site for endosseous implants [4].

Autogenous bone is considered the "gold standard" in grafting surgeries due to its properties of osteogenesis and osteoinduction [5,6]. However, it poses disadvantages such as high resorption rates, morbidity of the harvesting site and limited availability of intra-oral sources [6]. Other sources include allogeneic, alloplastic, and xenogeneic materials [7].

Allogeneic bone may be available in many forms, such as cancellous, corticocancellous, cortical graft, osteochondral, whole bone segment, and demineralized bone matrix. The graft integration 
process of allogeneic bone is similar to that which non-vascularized autogenous bone graft generally undertakes, but the size of the allograft influences the time of incorporation [8].

A transcutaneous submental approach was suggested for reconstruction of severely resorbed mandibles, where 4 to 6 dental implants were placed simultaneously with the bone graft to act as "tent poles" to maintain the height of the overlying mucosal soft tissue [9].

The aim of this article is to present a treatment workflow of mandible plexiform ameloblastoma with a unique reconstruction method, that can, in certain circumstances, replace the traditional one. The rationale of the study was to prevent side effects and complications following autogenic bone graft or osseocutaneous microvascular free flaps. The null hypothesis was that the non-autogenous reconstruction method can be used as an alternative treatment option in cases similar to the one presented.

\section{Case Presentation}

In August 2017, a 48-year-old male, was referred to Rabin Medical Centre for the evaluation of a $2 \mathrm{~cm}$ diameter exophytic mass located buccally to right anterior mandibular teeth (Figure 1). The patient is a former smoker (quit five years before referral time) and has diabetes mellitus, hyperlipidemia and oral sleep apnea. Resorption of alveolar bone and root deviation of the right lateral incisor was evident in dental X-ray (Figure 2) and in cone beam computed tomography (CBCT) imaging (Figures 3 and 4). In clinical examination, the tooth was vital and mobile class 3 according to Miller Classification. Incisional biopsy of the lesion was done (Figure 5) and revealed a plexiform ameloblastoma (Figures 6 and 7). Microscopically, a solid epithelial tumor was observed composed of interdigitating islands of odontogenic epithelium, with stellate reticulum-like areas, polarization of the basal nuclei and a dense matrix. The tumor cells were bland, lacking any sign of atypia. The final diagnosis was plexiform ameloblastoma.

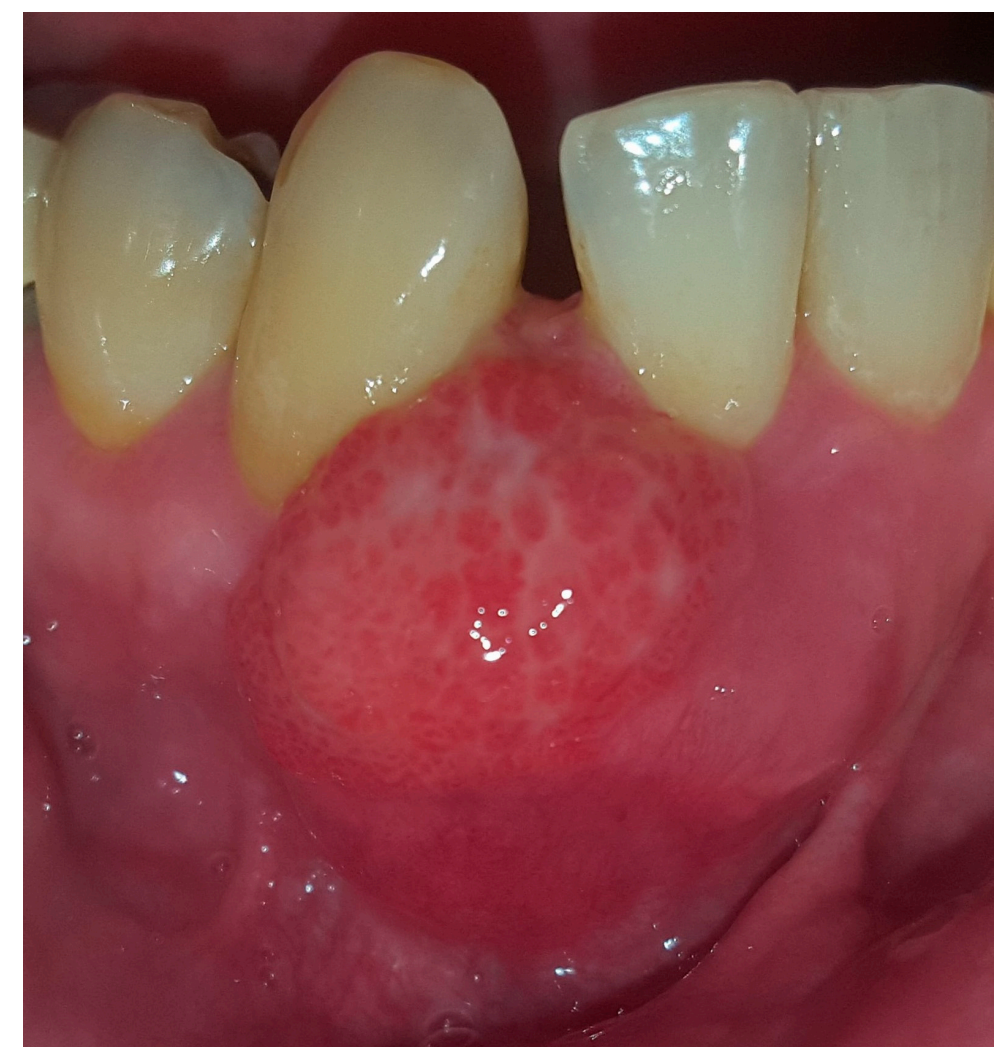

Figure 1. Reddish with white stripes exophytic $2 \mathrm{~cm}$ diameter mass located buccal to right anterior mandibular teeth. 


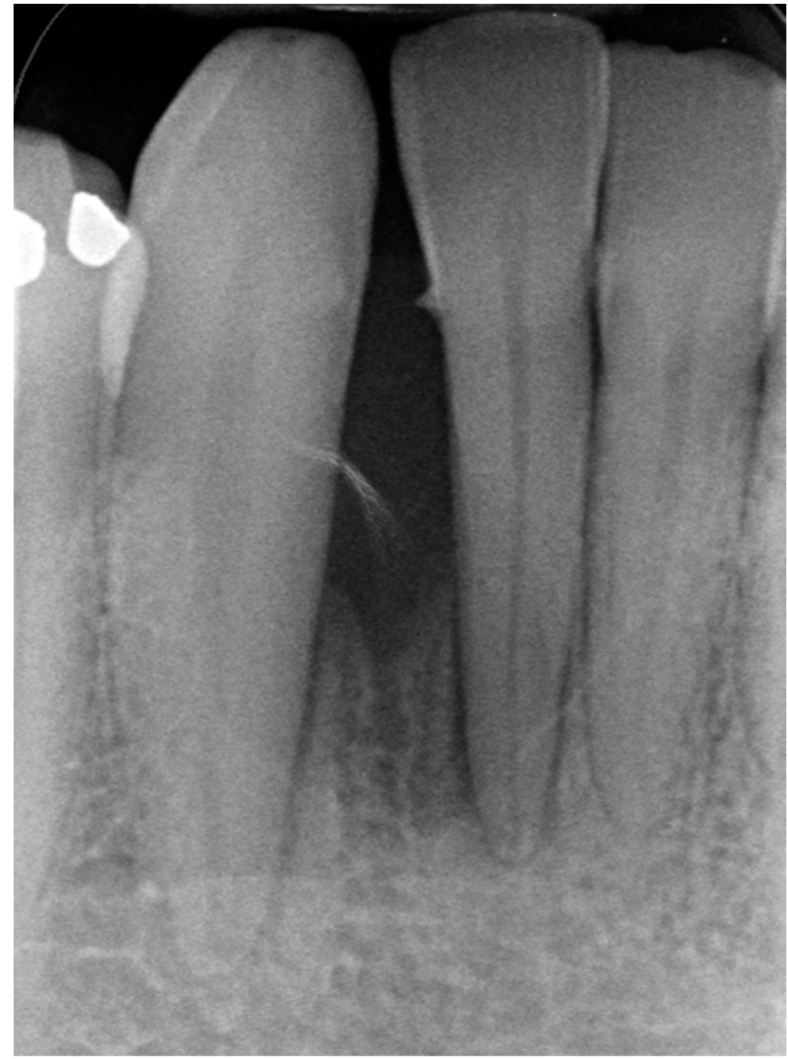

Figure 2. Resorption of alveolar bone surrounding and root deviation of lateral incisors as evident in dental X-ray.

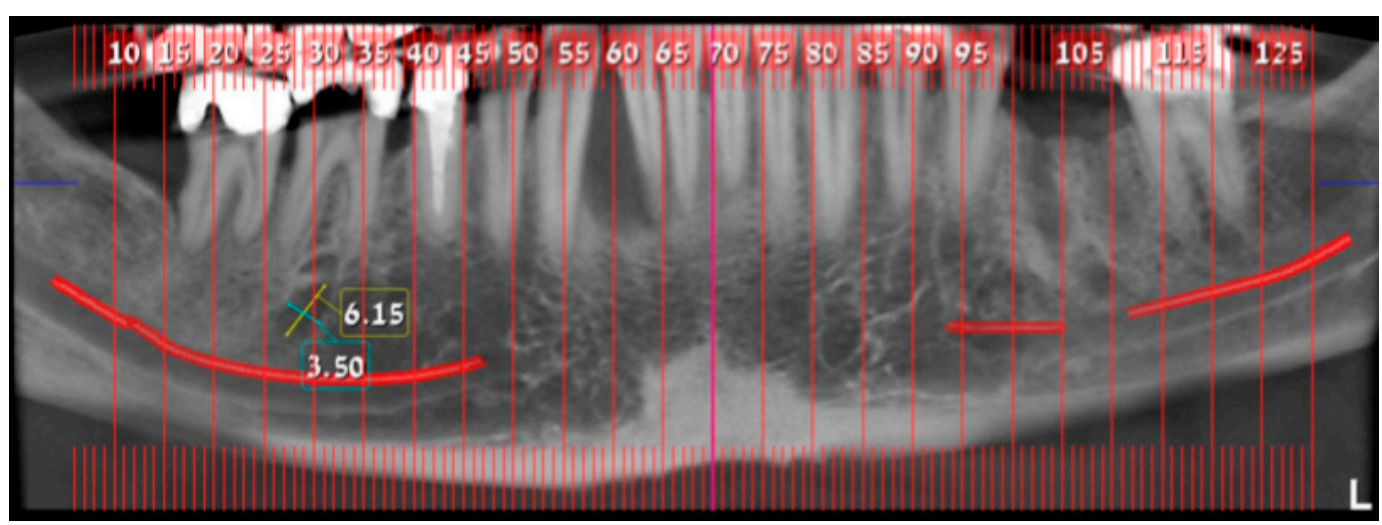

Figure 3. Resorption of alveolar bone surrounding and root deviation of lateral incisors as evident in CBCT (cone beam computed tomography, mentioned in the text above); panoramic image of reconstruction.

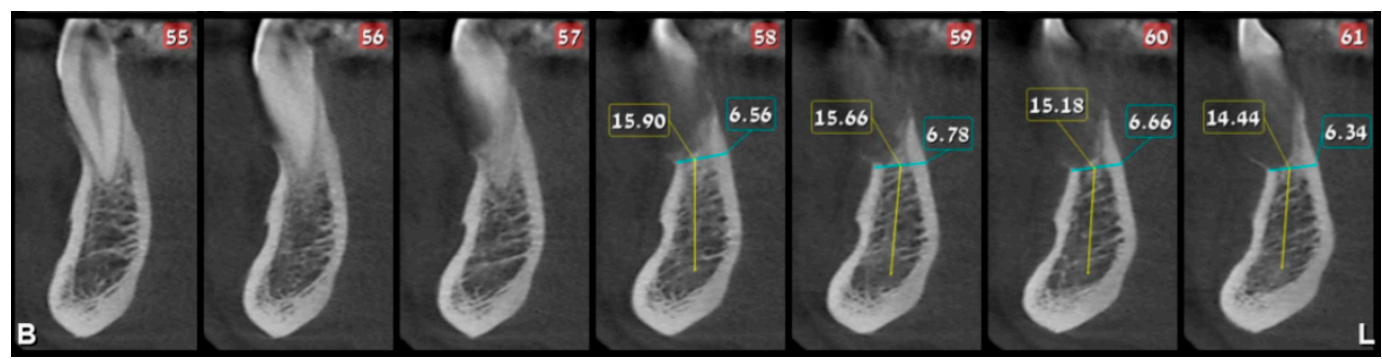

Figure 4. Cont. 


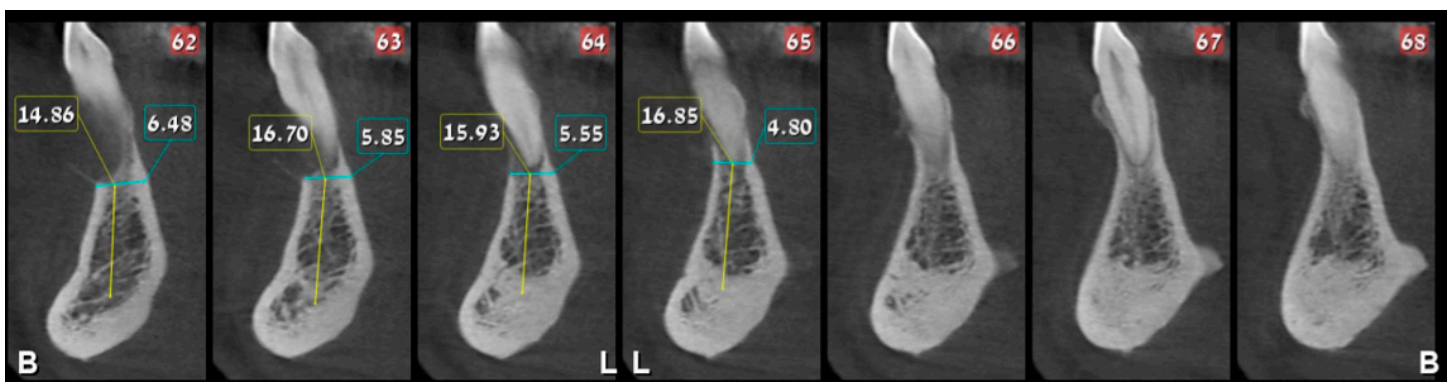

Figure 4. Resorption of alveolar bone surrounding and root deviation of lateral incisors as evident in CBCT; cross-sections of reconstruction.

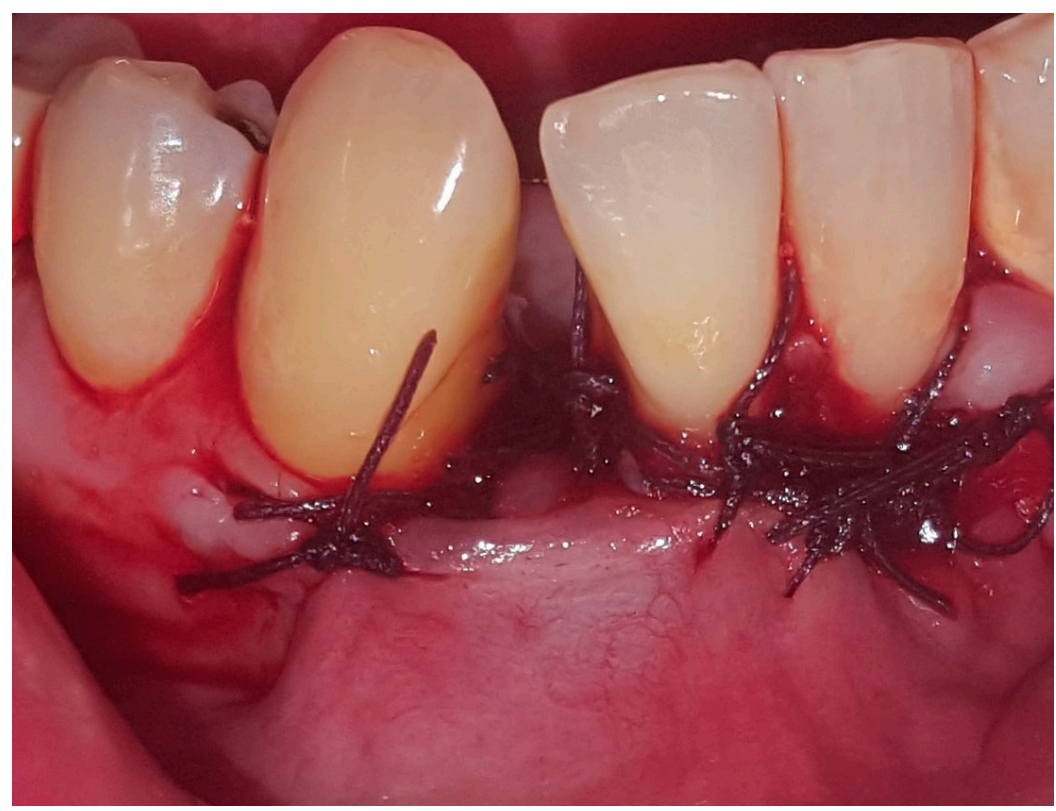

Figure 5. Clinical appearance following incisional biopsy and soft tissue suturing by 3-0 Vicryl.

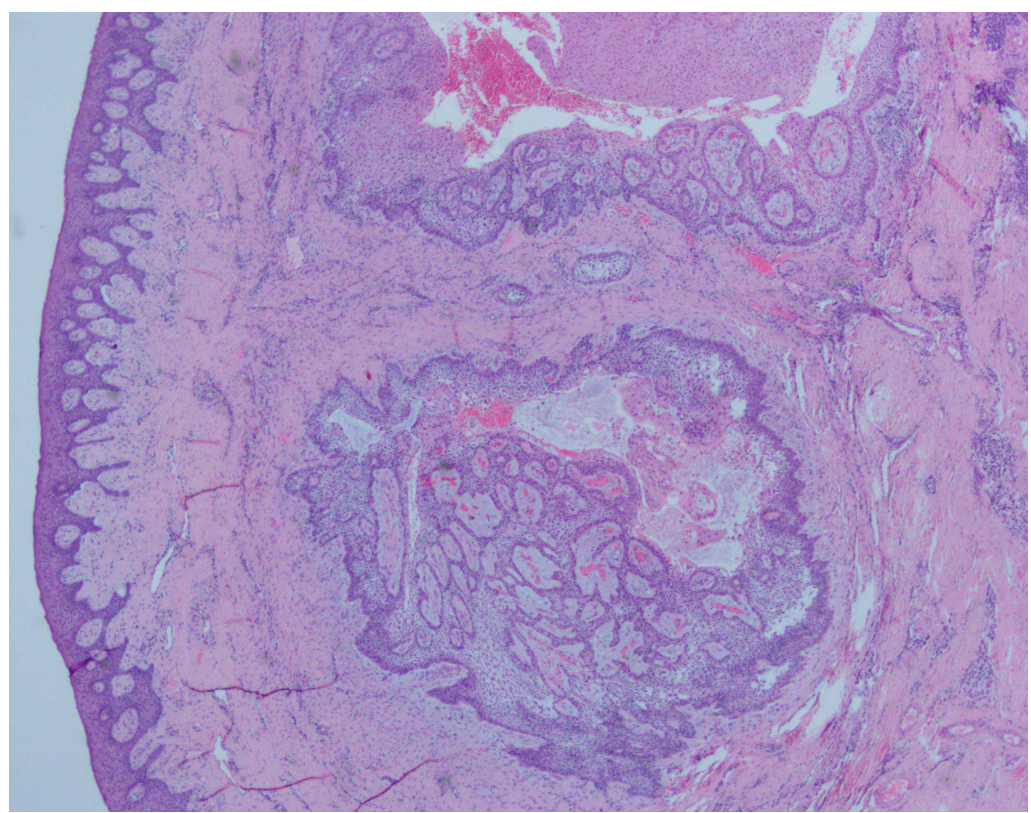

Figure 6. At low magnification, exhibiting islands of ameloblastoma in the sub-mucosa, with a plexiform architecture in a dense matrix $(H \& E$ original magnification $\times 40)$. 


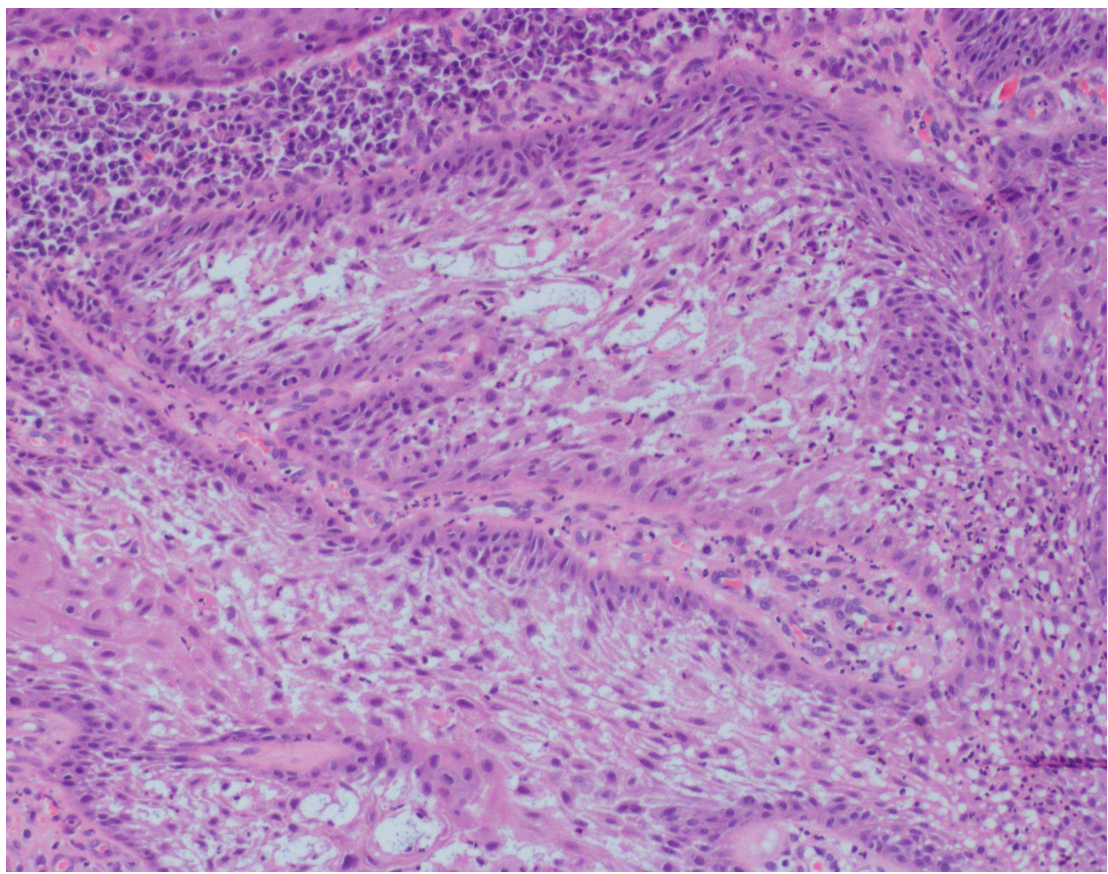

Figure 7. Polarization of the basal nuclei and stellate reticulum-like appearance of the cells in the central zone are demonstrated. (H\&E, original magnification $\times 200)$.

Having a finite diagnosis and under general anesthesia, the mass was resected with $1 \mathrm{~cm}$ free margins, resulting in marginal mandibulectomy (Figures 8-10). Following the resection, the patient received an Essix splint and gauze packing in order to allow secondary healing (Figure 11). Post-operative recovery was fair, with normal inferior alveolar nerve function and no evidence of recurrence during two years follow-up. A vertical defect of $2 \mathrm{~cm}$ in the anterior mandibular alveolar ridge was stable during the follow-up period as could be seen clinically (Figure 12) and by CBCT (Figures 13 and 14).

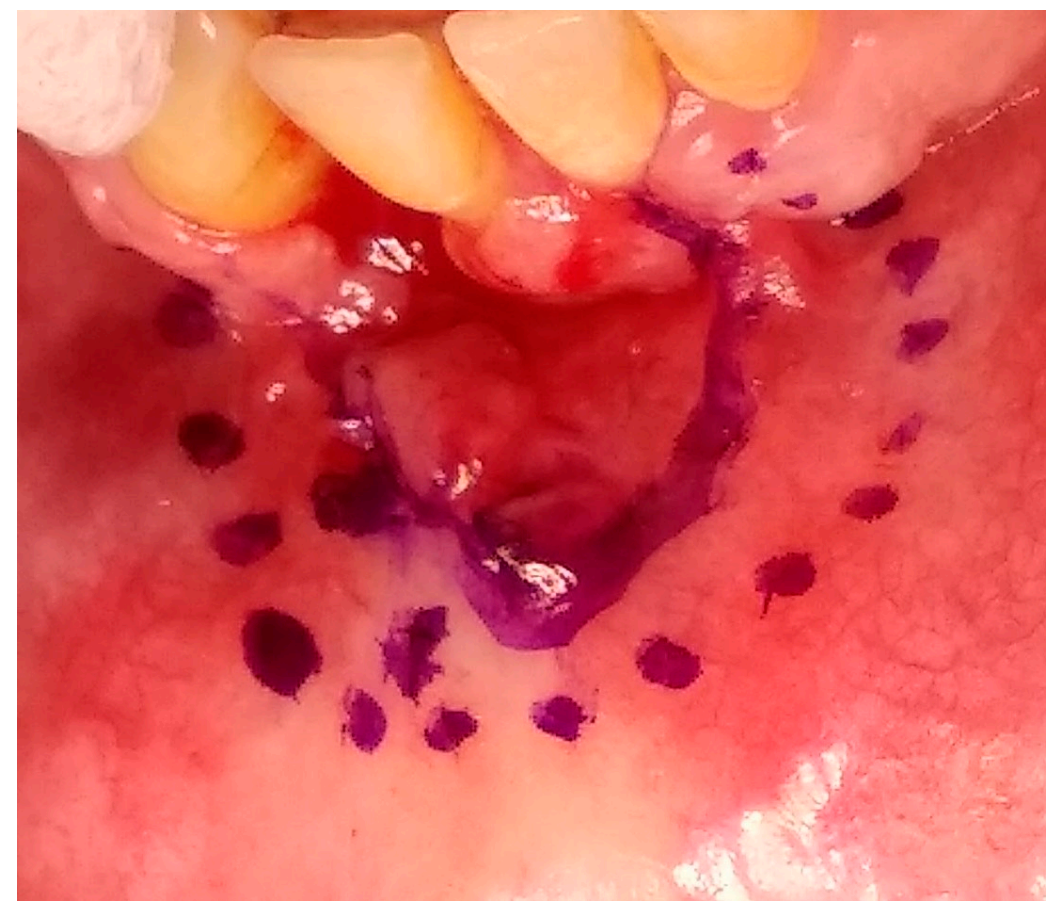

Figure 8. Tumor resection with $1 \mathrm{~cm}$ margins, soft tissue marking. 


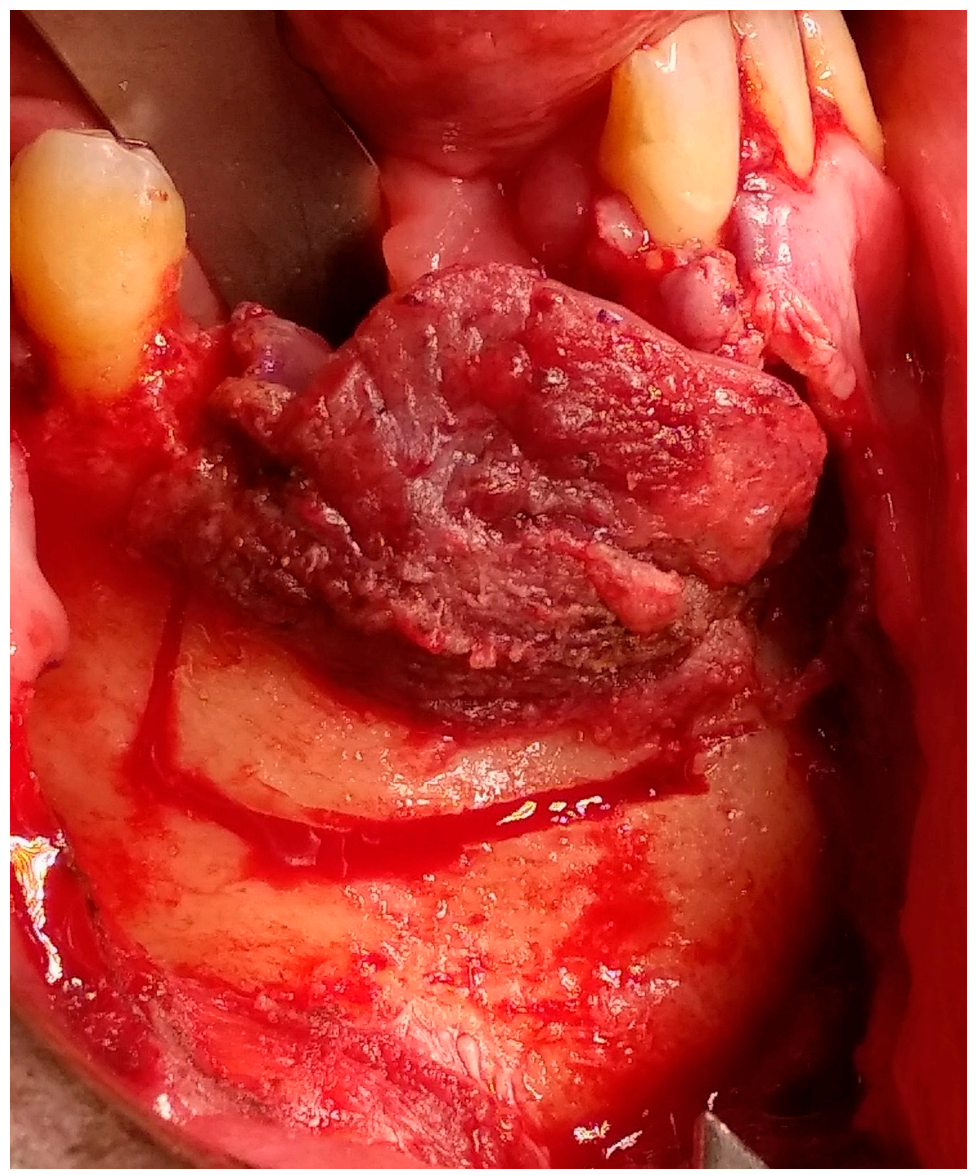

Figure 9. Tumor resection with $1 \mathrm{~cm}$ margins, osteotomy marking.

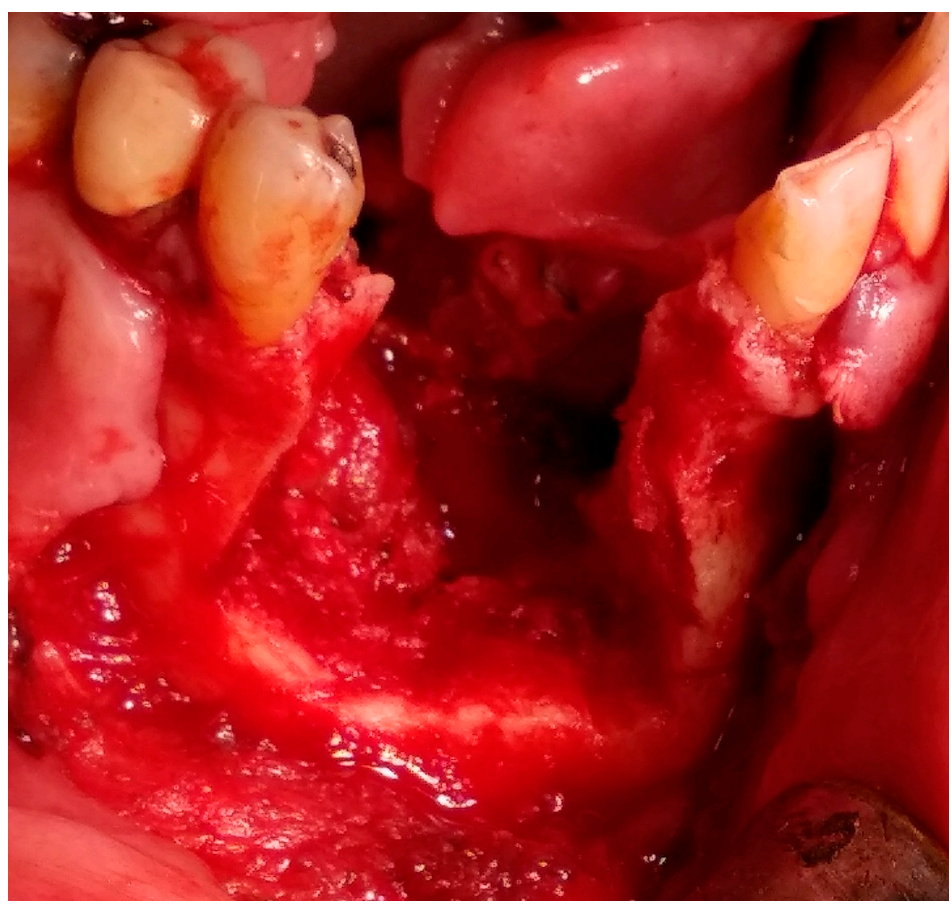

Figure 10. Tumor resection with $1 \mathrm{~cm}$ margins, resulting in marginal mandibulectomy. 


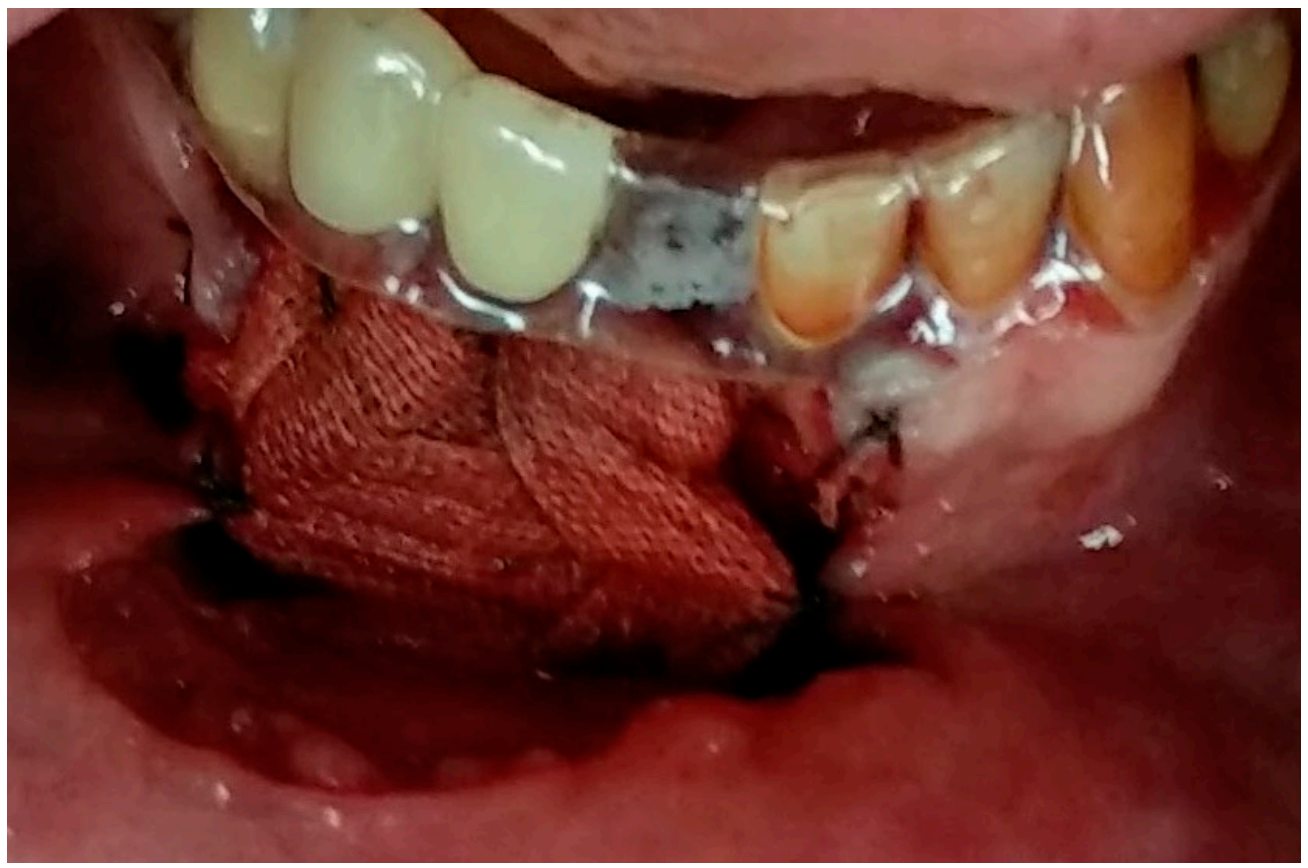

Figure 11. Essix splint on adjacent teeth and gauze packing in wound bed.

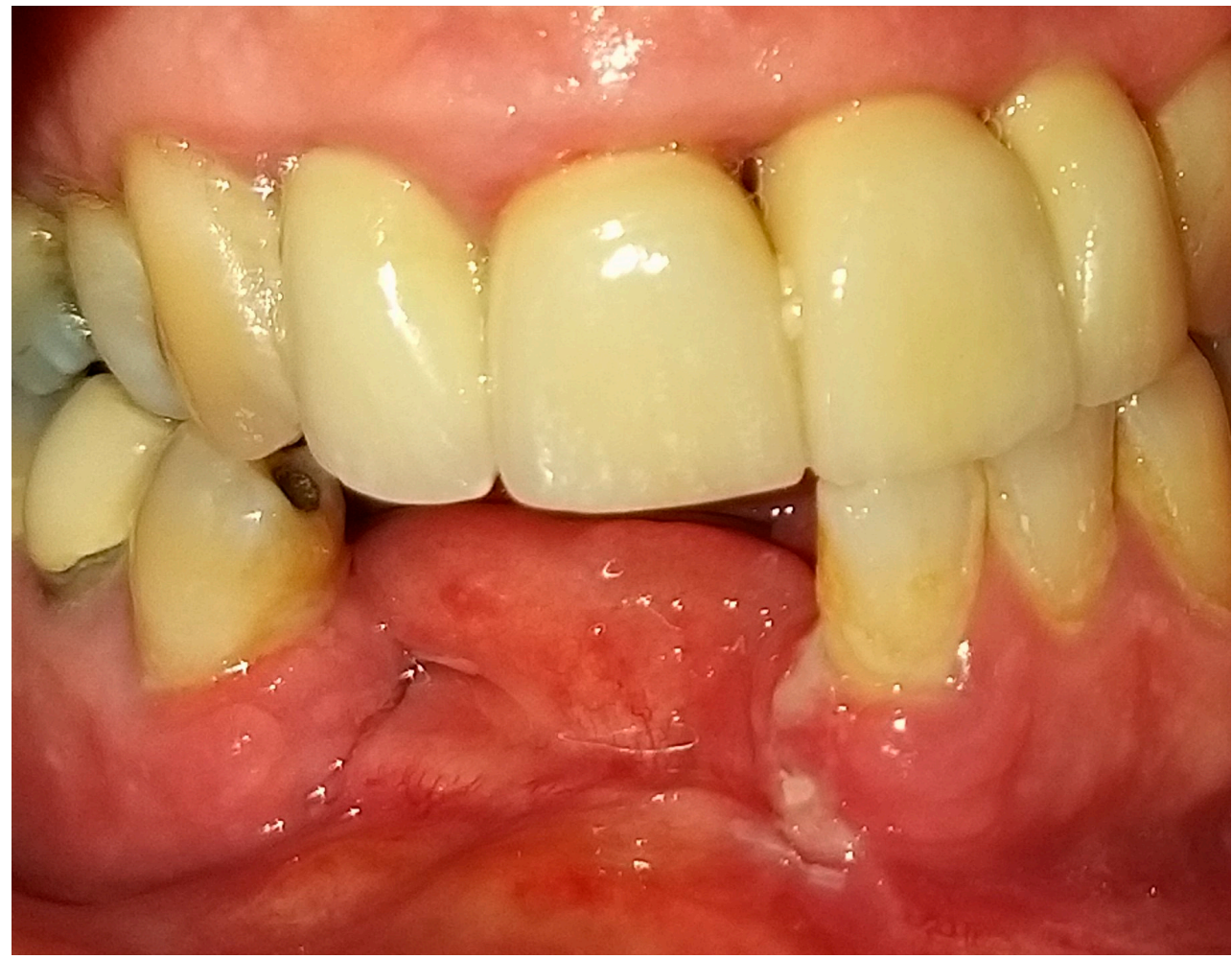

Figure 12. Clinical appearance of vertical defect in anterior mandibular alveolar ridge. 


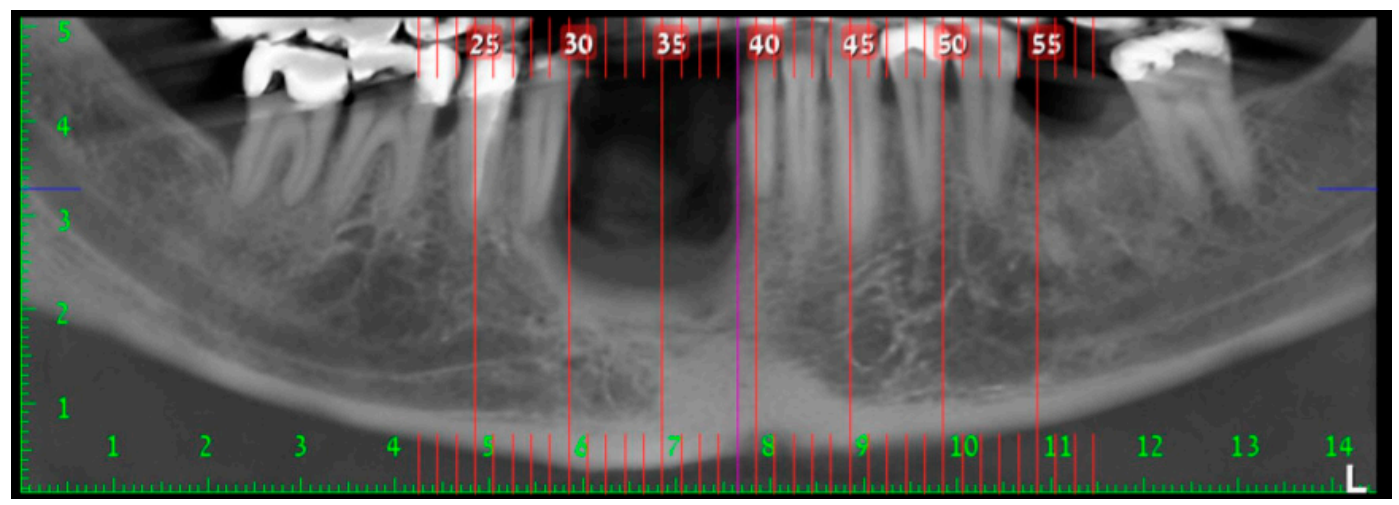

Figure 13. Two $\mathrm{cm}$ vertical defect in anterior mandibular alveolar ridge in $\mathrm{CBCT}$ imaging; panoramic image of reconstruction.

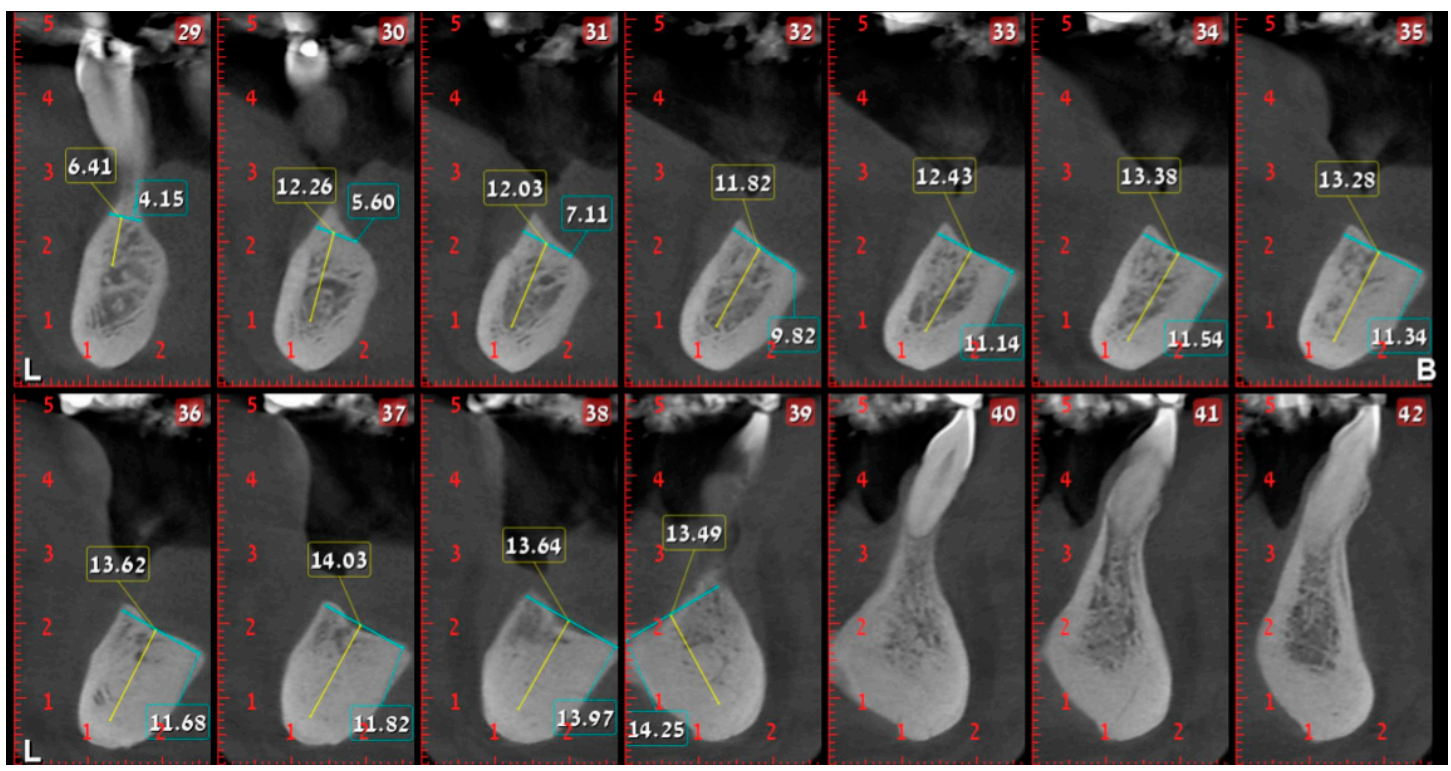

Figure 14. Two cm vertical defect in anterior mandibular alveolar ridge in CBCT imaging; cross-sections of reconstruction.

Reconstruction surgery was conducted by a submental transcutaneous "tent pole" approach in order to preserve oral soft tissue in the defect bed, maintain complete periosteum, and to separate the graft from oral cavity bacteria (Figure 15). The bony defect was exposed (Figure 16) and an allogenic bone block was fitted (Figure 17) and fixated by $2 \mathrm{~mm}$ thick titanium plate and screws (Figure 18). The block was covered with xenograft particles and cross-linked collagen membrane (Figures 19 and 20), and the soft tissue was sutured in layers (Figure 21). Four months following reconstruction surgery, the plate was reflected intraorally (Figure 22), and extraorally minimal submental scar was apparent (Figure 23). Bone gain was evident by CBCT (Figures 24 and 25). Two dental implants inserted through the grafted bone, were covered by xenograft particles and cross-linked collagen membrane (Figures 26-29). 


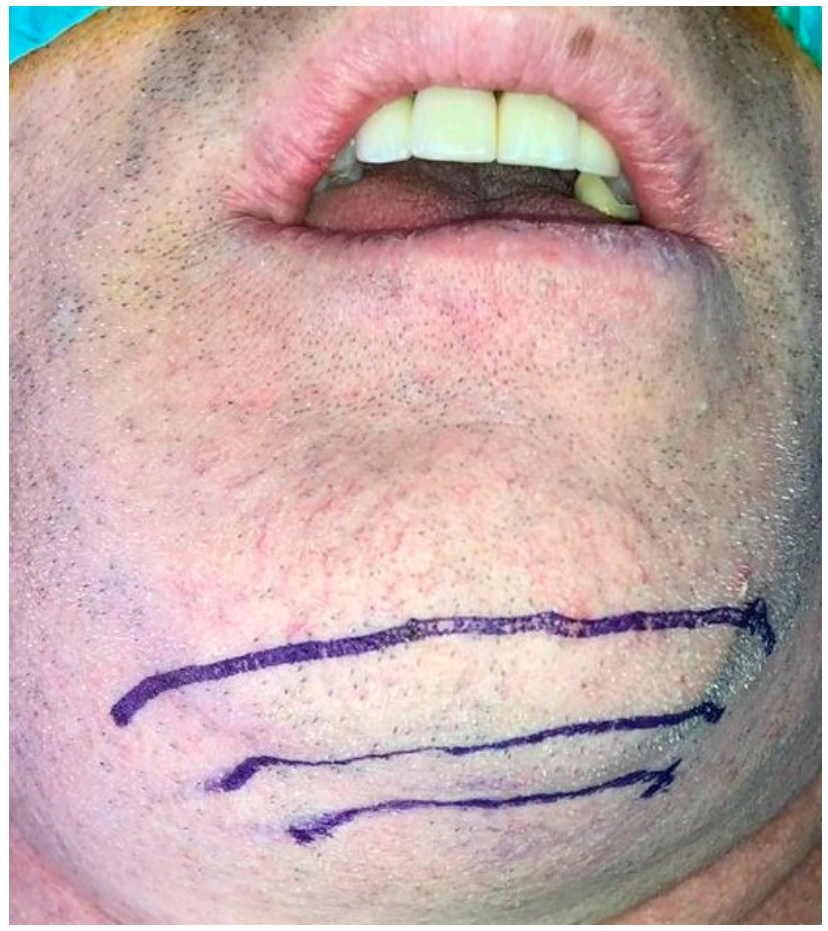

Figure 15. Submental transcutaneous tent pole approach markings.

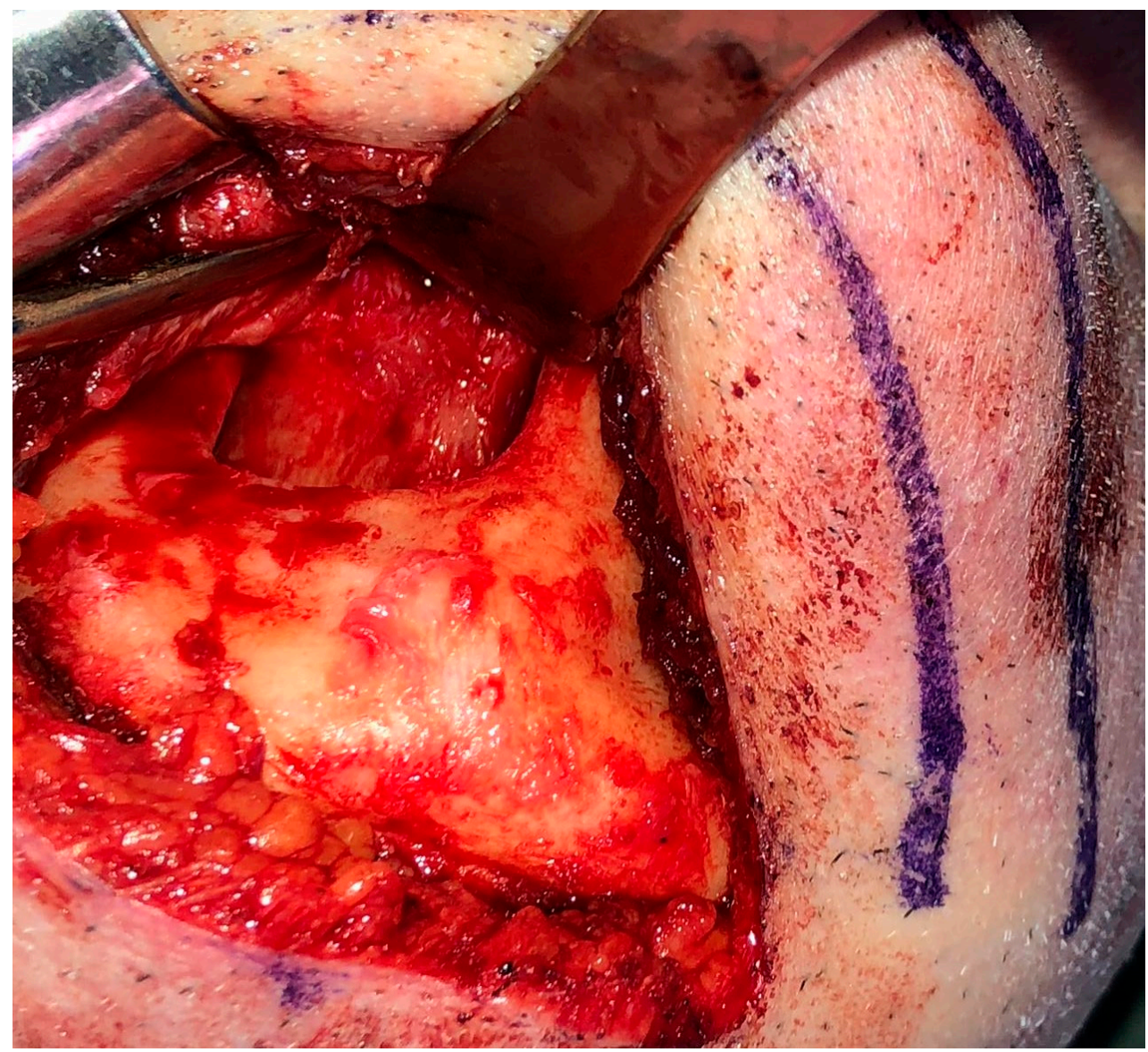

Figure 16. Defect exposure throughout submental transcutaneous tent pole approach. 


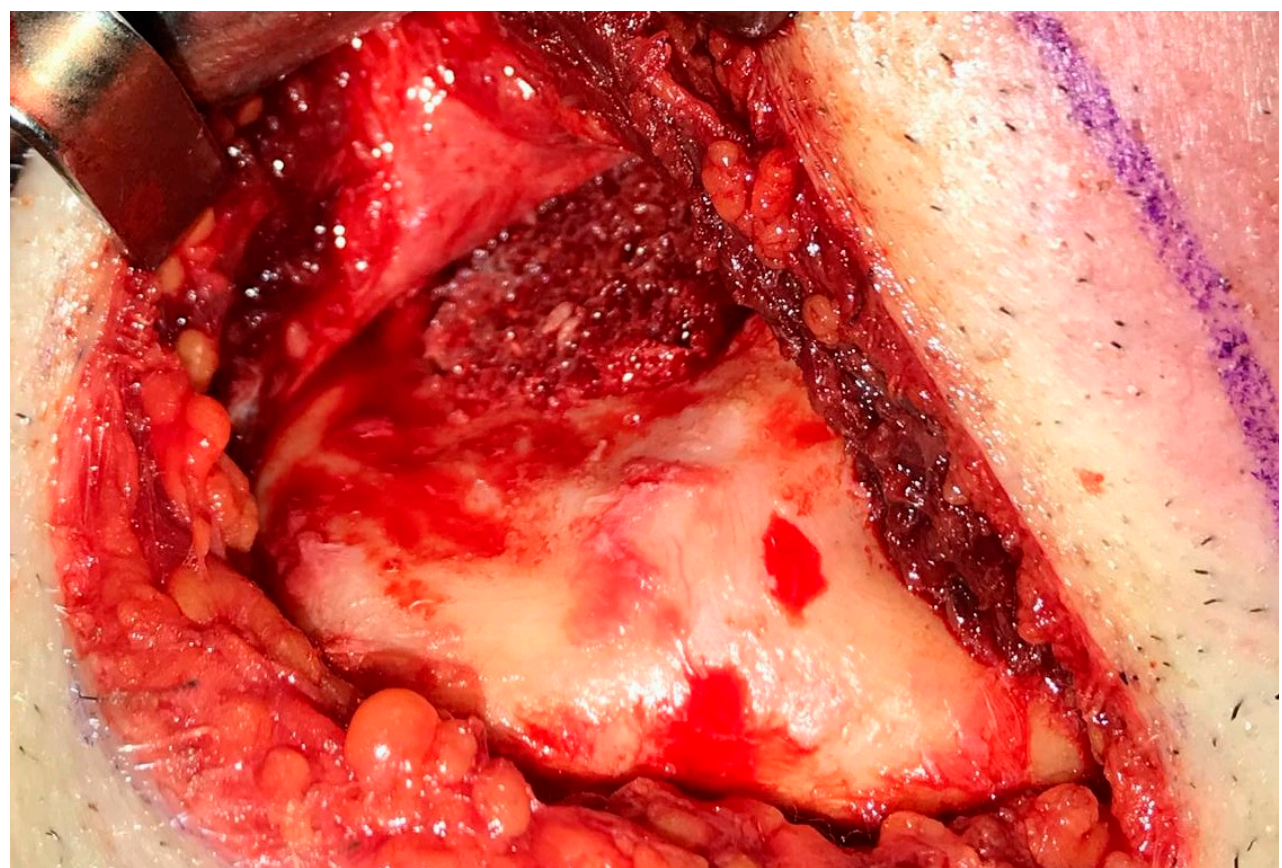

Figure 17. Allogenic bone block is fitted to the defect.

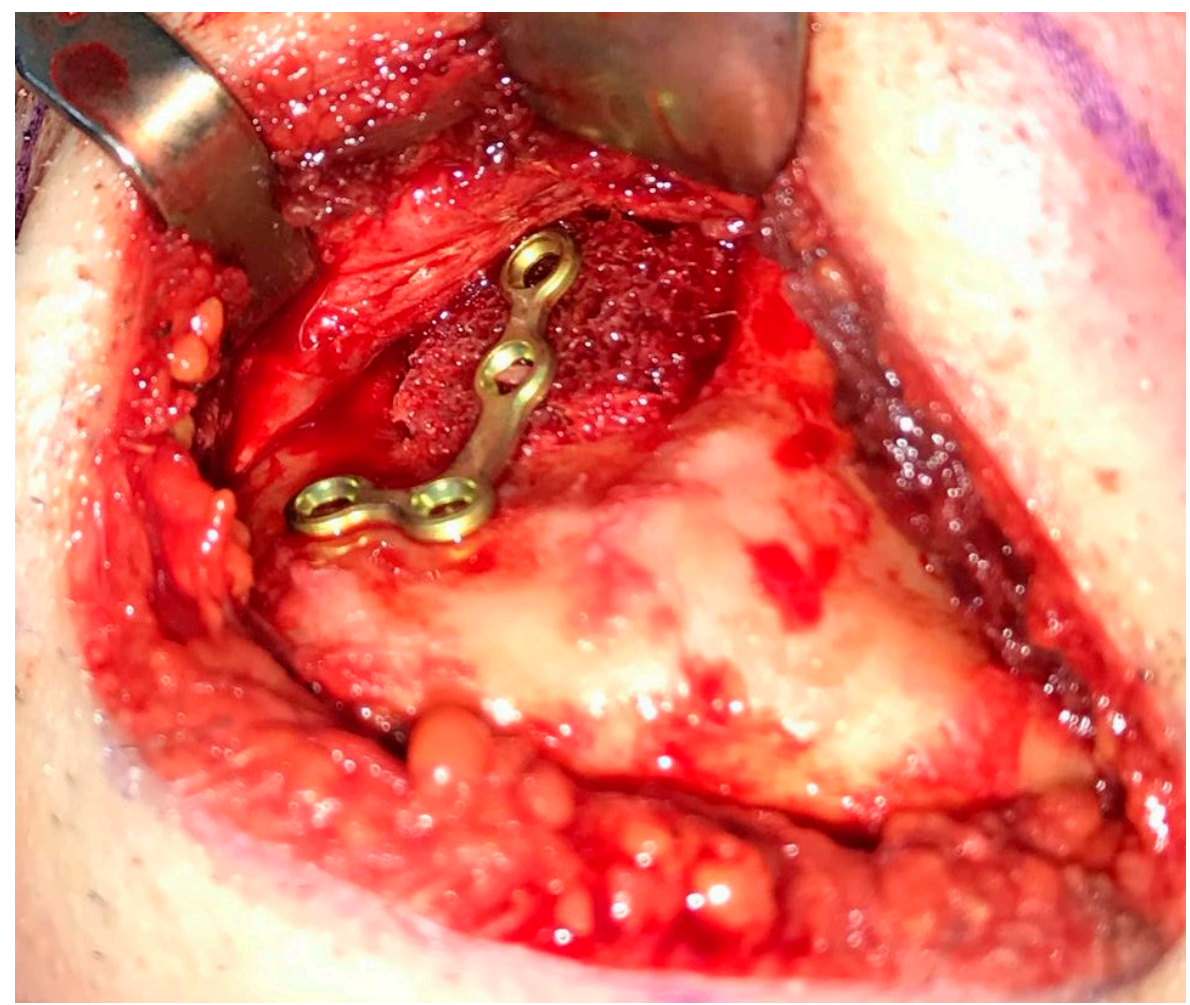

Figure 18. Allogenic bone block fixated to the alveolar ridge using "L" plate with 4 holes, $2 \mathrm{~mm}$ diameter and $7 \mathrm{~mm}$ length titanium screws. 


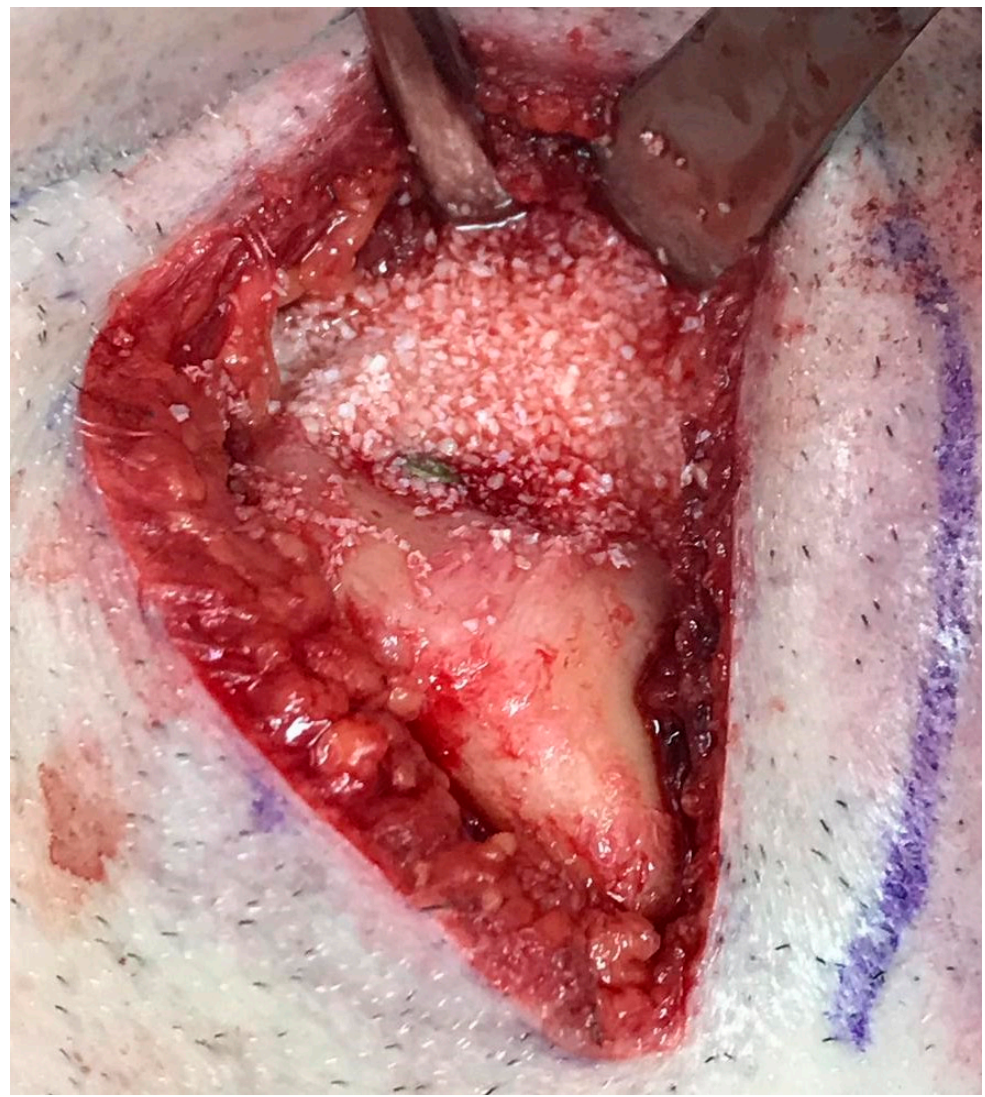

Figure 19. Allogenic bone block covered with xenograft particles.

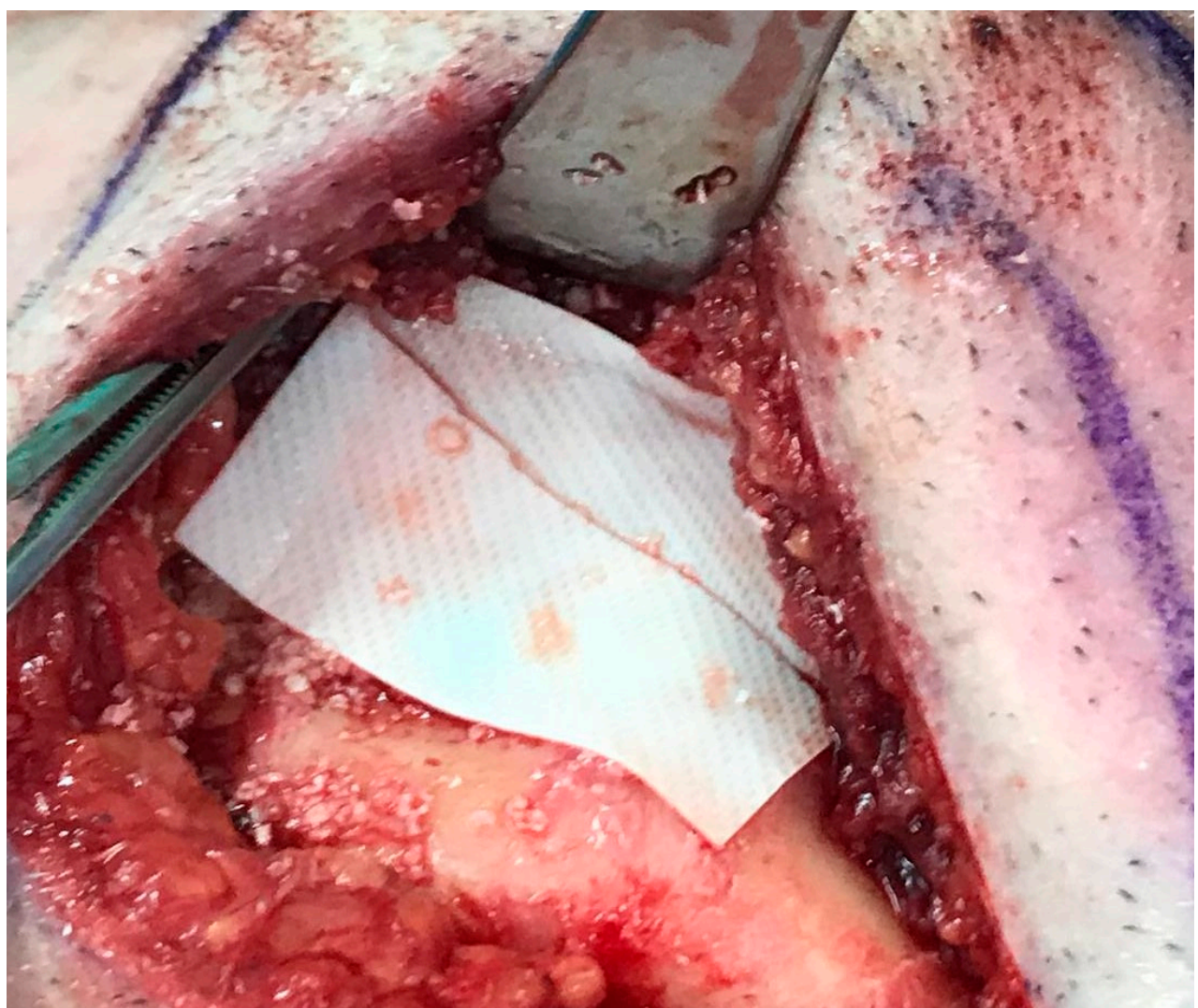

Figure 20. Allogenic bone block covered by cross-linked collagen membrane. 


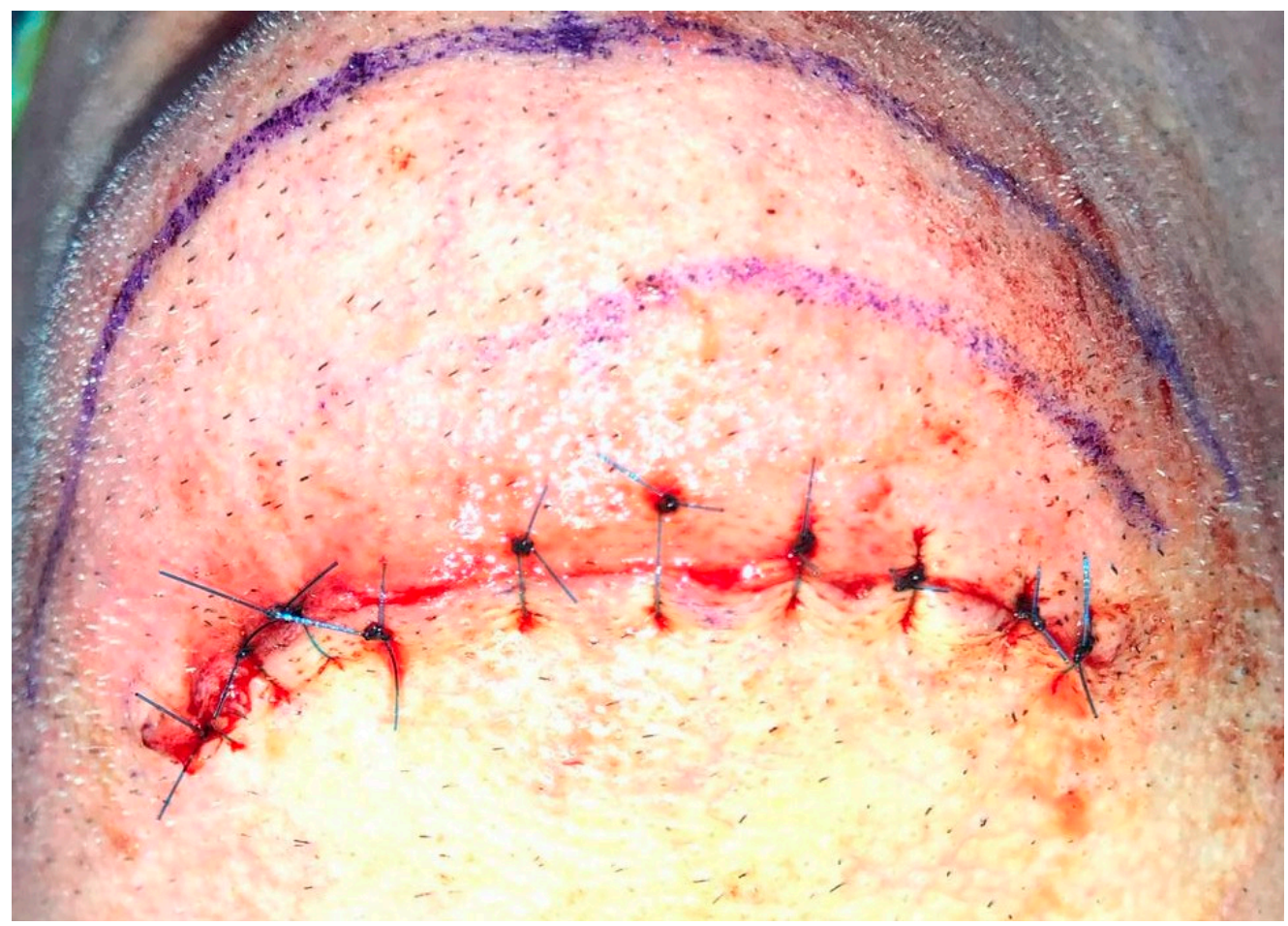

Figure 21. Tissue closure; suturing by layers.

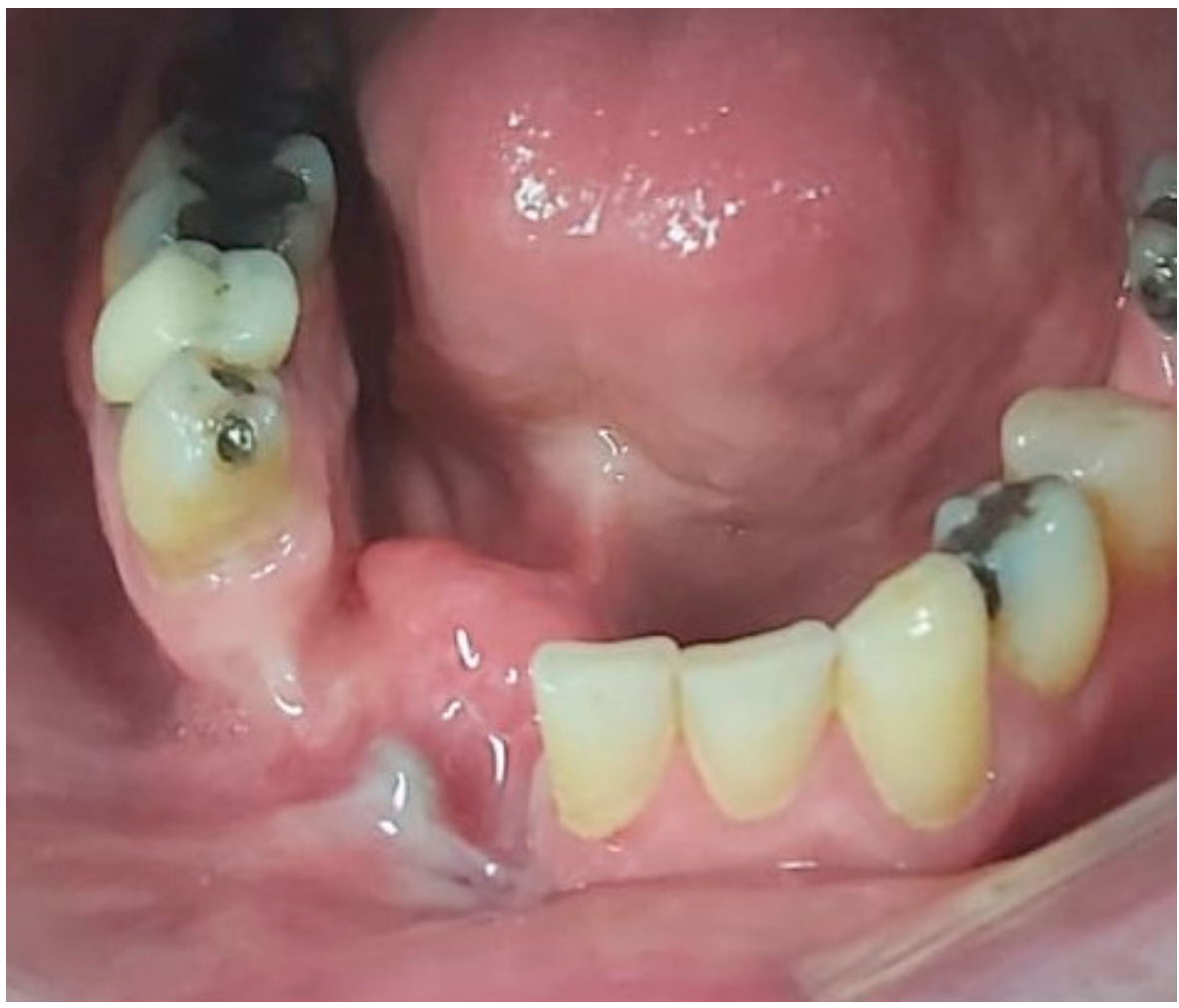

Figure 22. Clinical oral appearance 4 months following reconstruction surgery. 


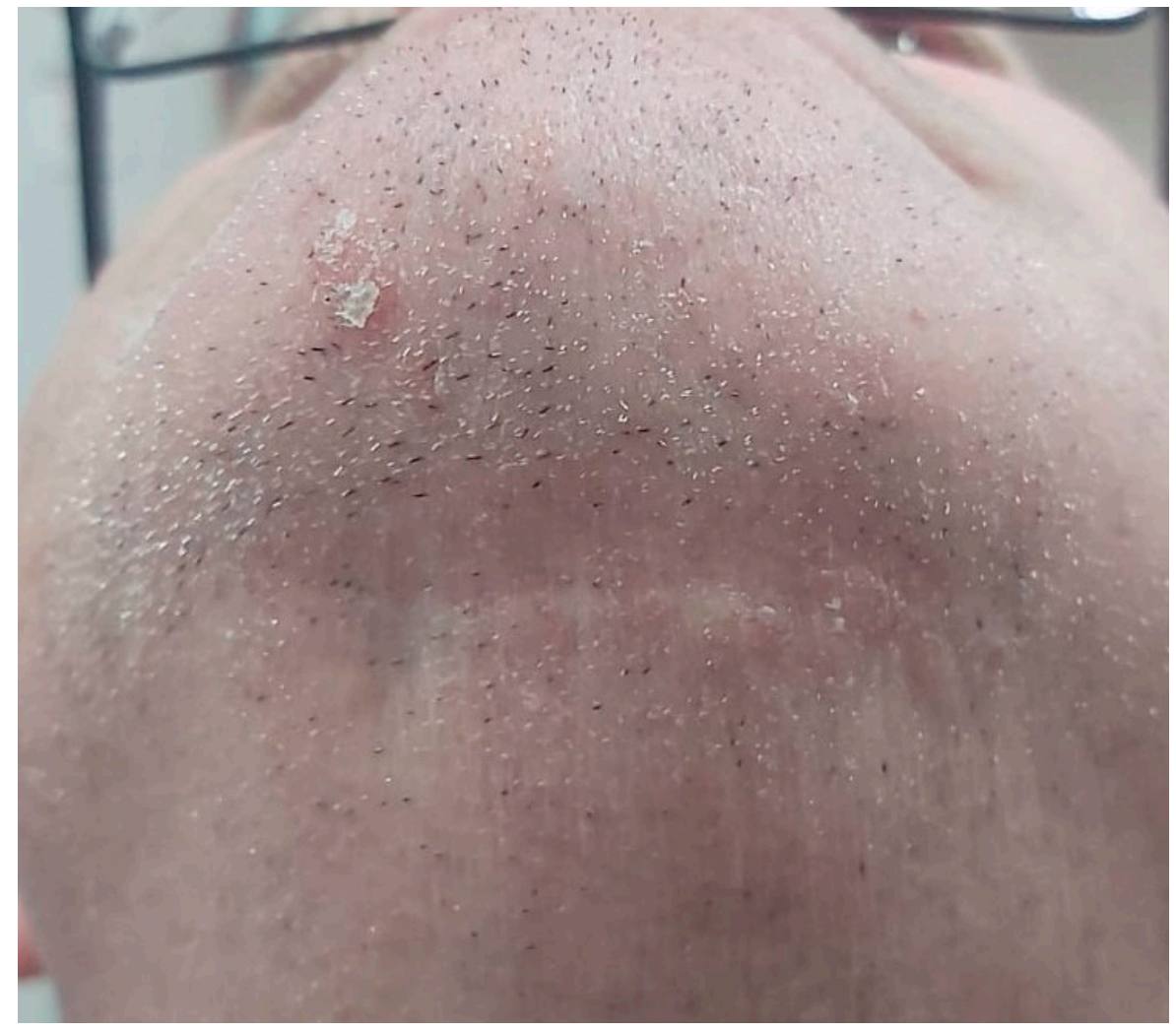

Figure 23. Transcutaneous submental scar 4 months following reconstruction surgery.

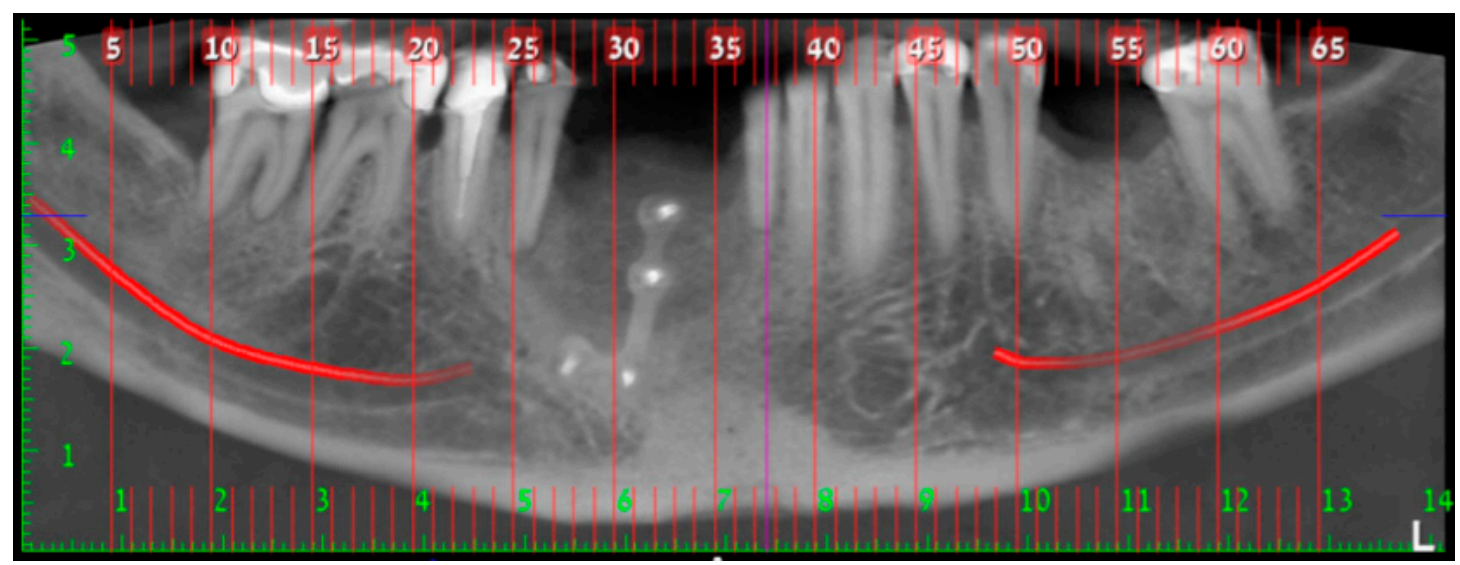

Figure 24. Alveolar ridge bone volume 4 months following reconstruction in $\mathrm{CBCT}$ imaging; panoramic image of reconstruction. 


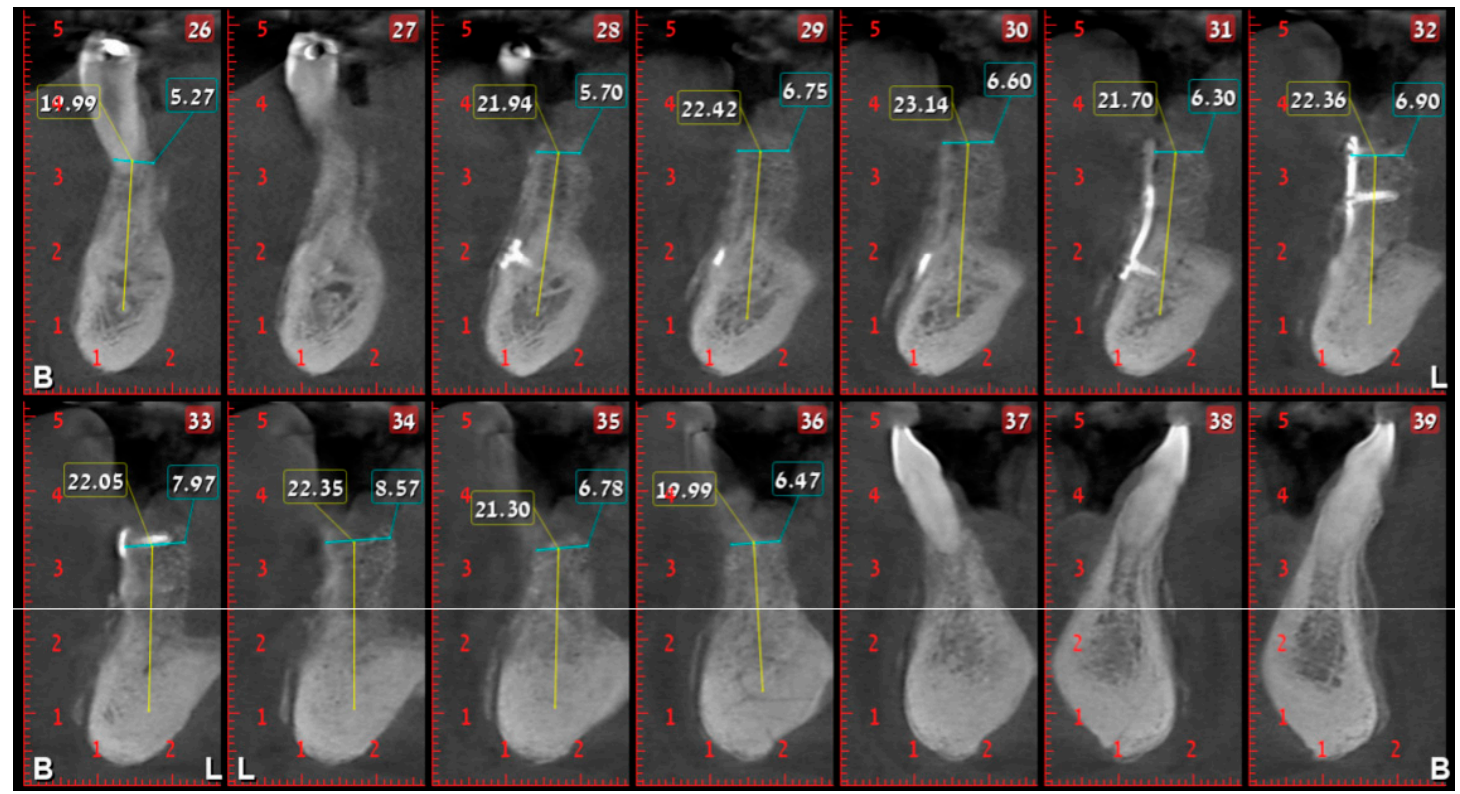

Figure 25. Alveolar ridge bone volume 4 months following reconstruction in CBCT imaging; cross-sections of reconstruction.

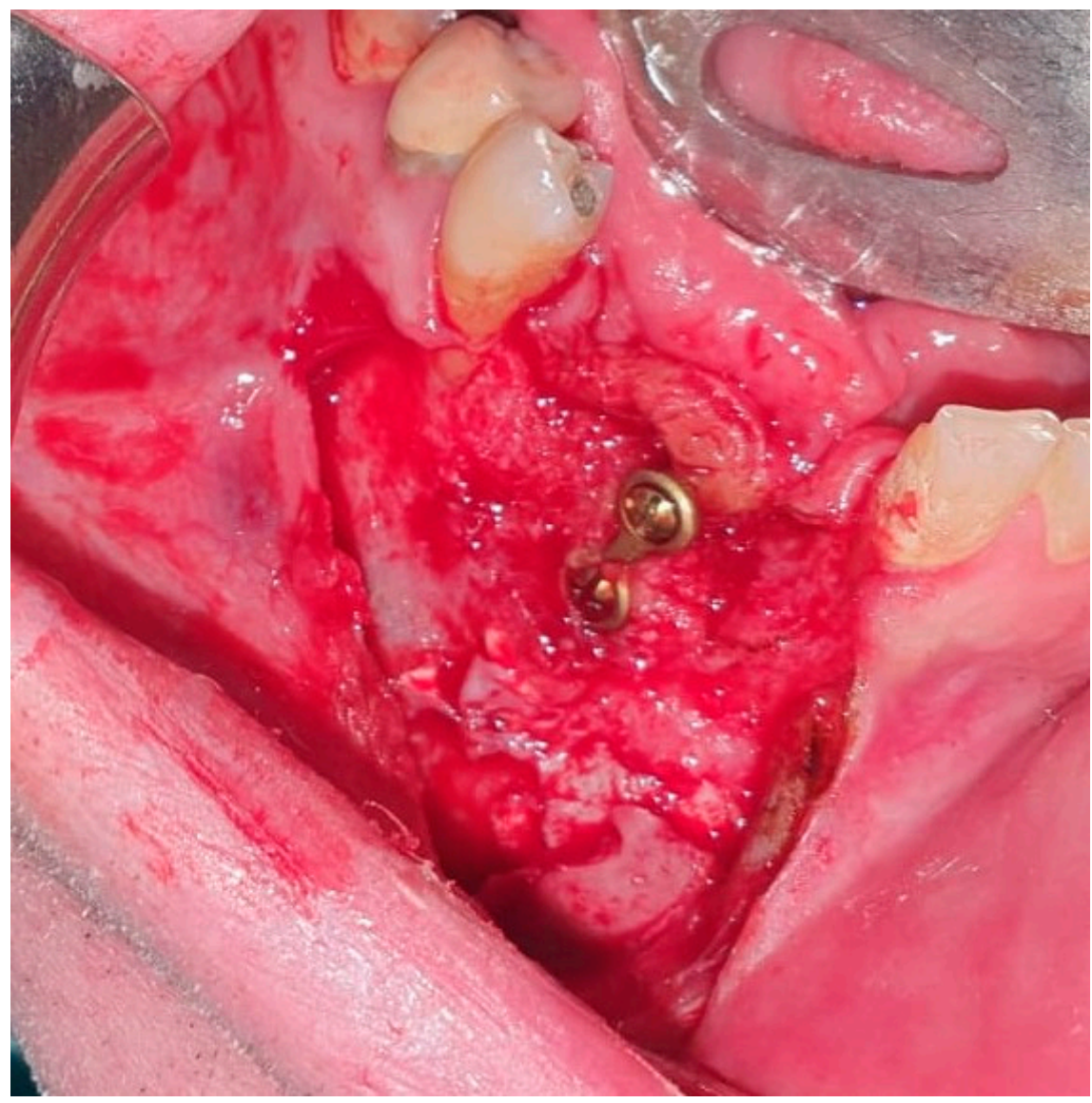

Figure 26. Clinical oral appearance of grafted bone 4 months following reconstruction surgery. 


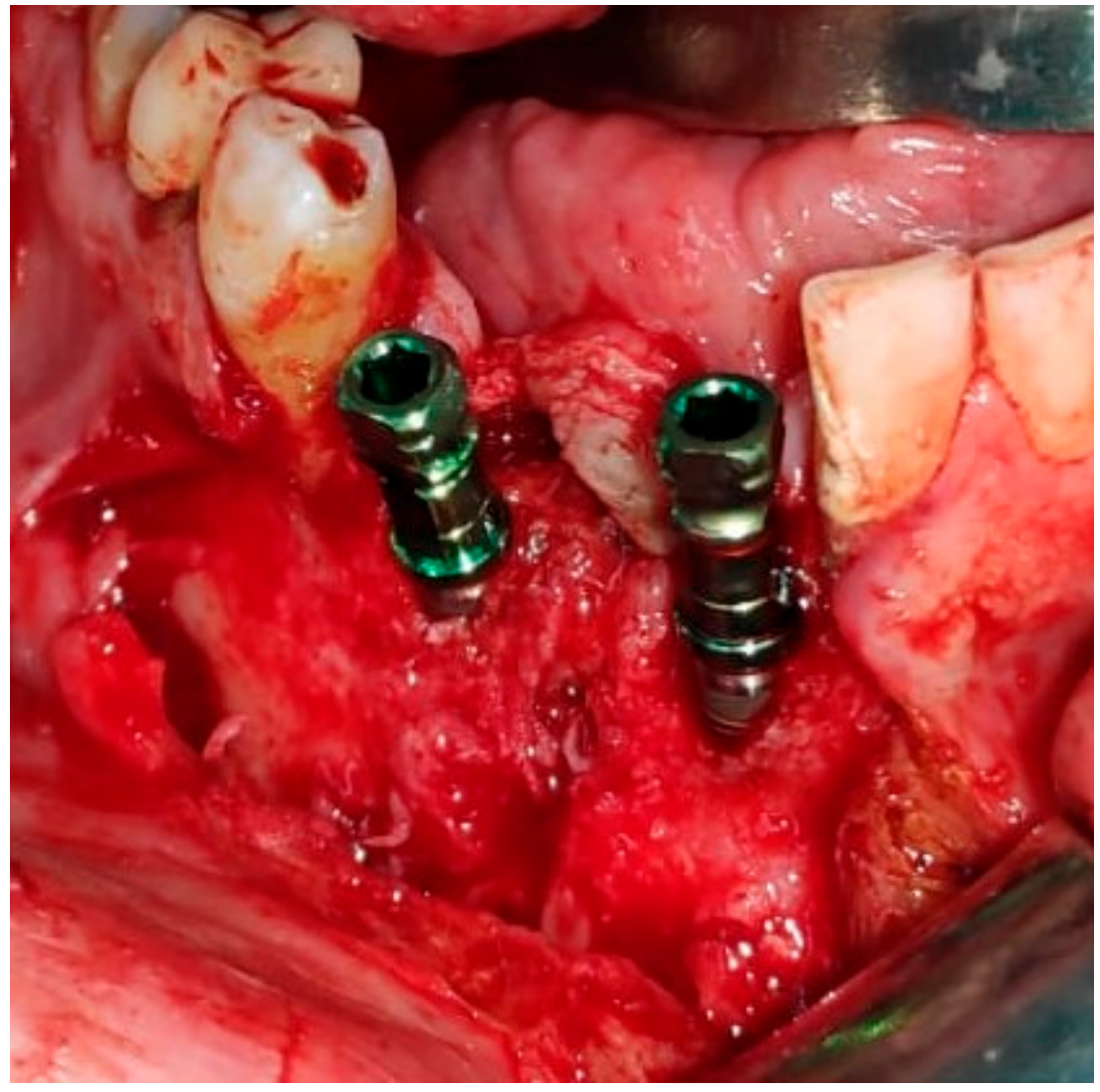

Figure 27. Two dental implants insertion through grafted bone.

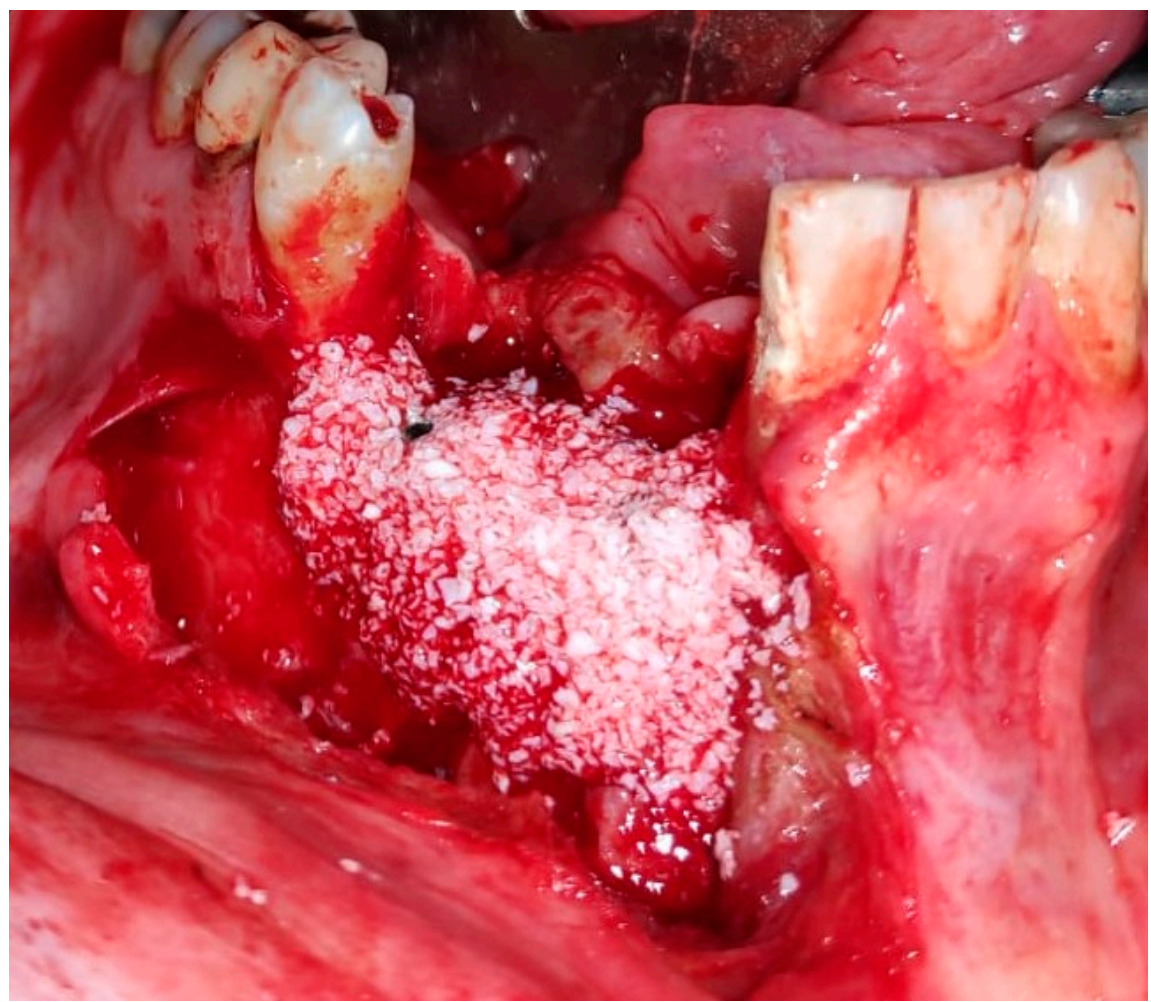

Figure 28. Xenograft particles covering dental implants. 


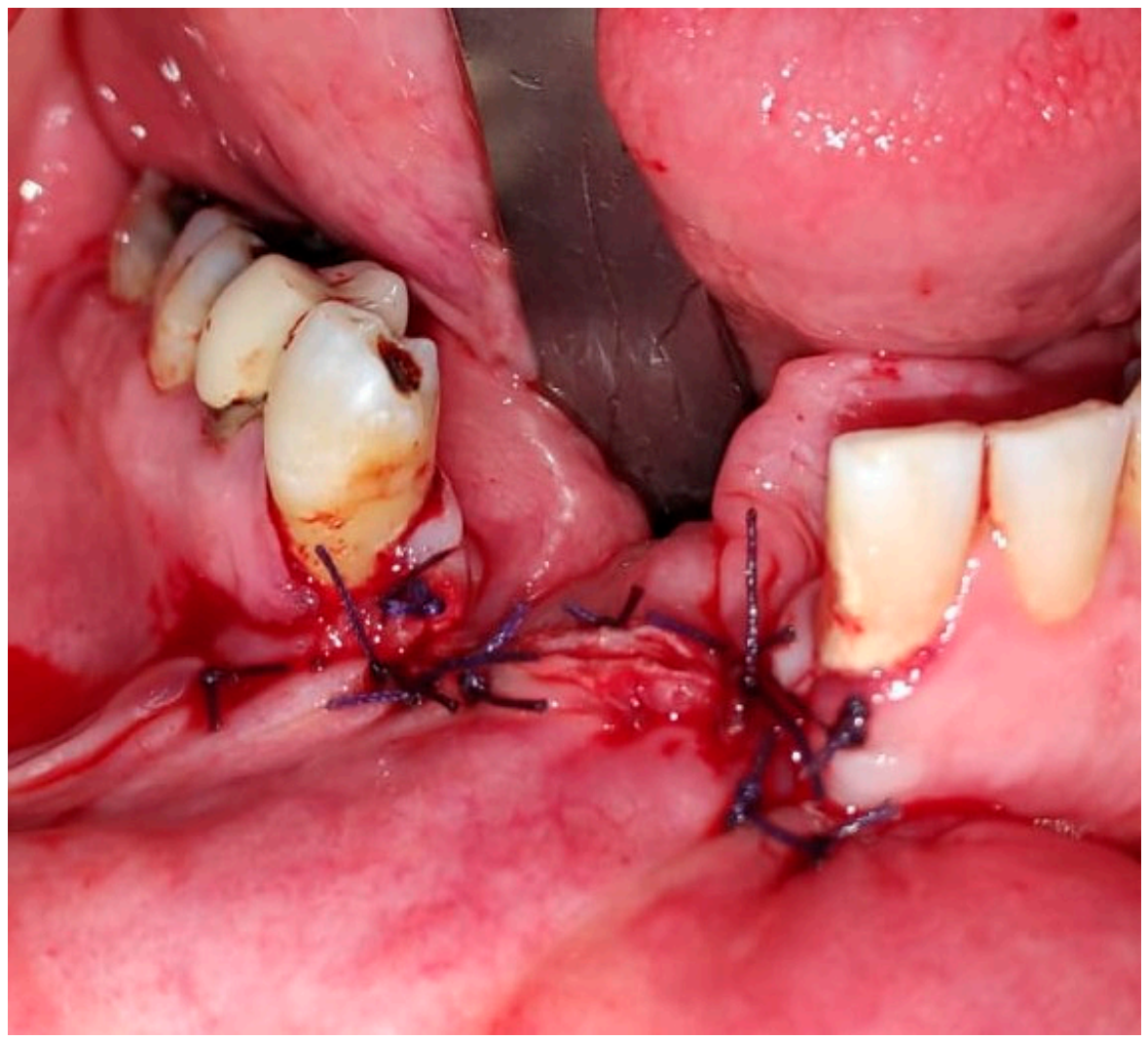

Figure 29. Oral tissue closure; suturing by 3-0 Vicryl.

Total admission days were nine, three days for each operation-resection, reconstruction and implants insertion. Medications prescribed post-operatively were penicillin-based antibiotics and painkillers such as paracetamol and dipyrone. No complications, such as bleeding, pus secretion, local heat and redness, were observed during admission days or during follow-ups.

\section{Discussion}

Accounting for $11 \%$ of all odontogenic tumors in the jaw, ameloblastomas affect mostly the ascending ramus and molar region of the mandible [1,2]. According to the World Health Organization (WHO) histopathological classification, there are seven types of ameloblastoma: plexiform, follicular, acanthomatous, granular cell, desmoplastic, peripheral and unicystic [2]. All ameloblastomas, excluding the latter two, have invasive diffuse borders and high recurrence rates, thus the clinical concept of 1 to $3 \mathrm{~cm}$ safety margin is needed, even though it is a benign tumor [1,3]. In the case presented, $1 \mathrm{~cm}$ of safety bony margin was chosen (Figures 8-10).

Reconstruction of bony defects after resection of ameloblastoma remains a major concern for both patients and clinicians [10]. Evaluating the host and classifying of the bony defect can guide the surgeon to patient-specific reconstructive options. The defect involved in the case presented is a two-wall defect, $2 \mathrm{~cm}$ vertical and $2 \mathrm{~cm}$ latero-lateral sized. Acceptable reconstruction options were distraction osteogenesis (DO), osseocutaneous microvascular free flaps, autogenic bone graft, guided bone regeneration (GBR), and allogenic bone graft. According to a recent systematic review and meta-analyses, if more than $4 \mathrm{~mm}$ vertical ridge augmentation is needed, as in the case presented, the GBR technique is less effective and predictable [11]. The presented defect was defined as under the critical size according to Pogrel et al., and thus, we were able to avoid the second and third options, sidestep high resorption rate, and high morbidity following harvesting [12]. DO, involving an osteotomy and gradual elongation of bone using an intra oral device is based on the "tension-stress" principle described by Ilizarov, and can be a good treatment solution, suitable to the amount of bone 
available in the case (more than $8 \mathrm{~mm}$ vertical anterior mandibular bone) [13]. However, it poses high rates of complications; minor, moderate and severe in $58 \%, 8 \%, 3 \%$ of patients respectively [14].

A good prognostic factor in the case presented is the remaining of vital bone source, since the patient had benign pathology and has not received chemo- or radio-therapy following resection. Vital remaining bone source is able to secrete growth factors and hasten the blood supply for the non-vascularized grafted bone. The clinical and radiographical results of this case, according to all factors discussed, emphasized that the defect presented could be suitably reconstructed by non-vascularized bone graft.

Recombinant human bone morphogenetic protein (rhBMP) is a genetically engineered version of the cytokine that is chemotactic for mesenchymal stem cells and induces their differentiation into osteoblasts [6]. Due to its osteogenic properties, rhBMP has shown its predictability and efficiency. The main function is signaling for regeneration, which promotes differentiation of the stem cells and migrating osteogenic cells $[15,16]$. Other important factors included in tissue engineering are the scaffolding that is provided by allogenic bone which acts as a framework for bone regeneration, and regenerative cells that are provided by bone marrow aspirate concentrate (BMAC) [17].

A main regenerative concept in bone regeneration is the use of mesenchymal stem cells (MSCs). The oral cavity is populated by MSCs that can be isolated in an easy way and with minimal invasive procedures [18]. Human periapical cyst mesenchymal stem cells (hPCy-MSCs) have features comparable to other dental-derived MSCs. A recent review study by Tatullo et al. [19] stated that this cell population exhibits valuable potentialities that could be of high impact in future regenerative medicine applications, as presented in this case. Recent reports have demonstrated the ability of MSCs to be activated by signals from injured tissues. In these damaged areas, MSCs showed regenerative behavior, promotion of tissue healing, paracrine activities, and secretion of anti-inflammatory factors [20]. A recent special issue, edited by Ballini et al. [21], addressed MSCs in "their different but fundamental roles as promoters, enhancers, and playmakers of the translational regenerative medicine."

In the case presented, the allogeneic block bone graft serves as a resorbable scaffold. The cancellous portion of the allogeneic block is porous and allows more rapid revascularization and cellular ingrowth. The combination of rhBMP and cancellous allogeneic block, as chosen in the presented case, can complete the "tissue engineering triad" (cells, signaling molecules and scaffold) and more closely matches the properties of autogenous bone [6].

The stress on the chosen scaffold-allogeneic block bone, was not evaluated. Future research can evaluate stress on biomaterials that can be used as a scaffold in bone regeneration, such as the "three-points bending test." The test, as described by Merrelli et al. [22], may be used to "evaluate these materials' tolerance to biomechanical forces exhibited by oral cavity tissues."

To improve the survival rate of the grafted bone, the reconstruction surgery was done via the transcutaneous submental "tent pole" approach, presented by Marx et al. [10]. The approach preserves oral soft tissue in the defect bed and separates the grafted bone from oral cavity bacteria. An additional crucial advantage is keeping the periosteum complete and vital throughout the whole process. Adult human periosteum is highly vascular, retains the ability to differentiate into diverse cell types and accelerates new bone formation underneath it [23]. The success of the bone graft and dental implants highly depends on the blood supply coming from the host tissue. Recent studies by Isola et al. emphasized the importance of vitamin D and malondialdehyde in this complex process [24,25]. One of the main functions of vitamin $\mathrm{D}$ is in the regulation of serum calcium levels, alveolar bone growth and periodontal ligament homeostasis [26].

Extraoral esthetics achieved using the approach are high (Figure 23), and the scar is minimal and almost invisible in natural head position [27]. Placement of the submental incision posterior to the submental crease, as done in the case presented (Figures 15 and 16), will result in an inconspicuous, well-concealed scar [27]. Roh examined clinical outcomes of the submental approach, compared with a conventional submandibular approach, for submandibular gland resection and concluded that the scar results in the former were usually less visible and the patient satisfaction score was higher [27]. 


\section{Conclusions}

Mandible reconstruction modalities have a crucial influence on patient quality of life, function and esthetics. This case report presents an alternative treatment in which an allogenic bone block combined with rhBMP and xenograft particles can replace the traditional autogenous bone in specific cases. The submental transcutaneous "tent pole" approach can preserve oral soft tissue in the defect bed, maintain complete periosteum coverage and separate the graft from oral cavity bacteria. In this way it can improve the success rate of the reconstruction procedure. For future studies, important factors such as vitamin D and malondialdehyde should be monitored as they have an impact on graft and dental implant success [24,25].

Author Contributions: Conceptualization, G.C. and B.H.Y.; methodology, Y.B.-Z. and E.R.; investigation, Y.H.; resources, E.R. and B.H.Y.; writing - original draft preparation, Y.H., I.K. and Y.B.-Z.; writing-review and editing, Y.H.; project administration, G.C. All authors have read and agreed to the published version of the manuscript.

Funding: This research received no external funding.

Conflicts of Interest: The authors declare no conflict of interest.

\section{References}

1. Martins, R.H.; Sobrinho, J.D.A.; Rapoport, A.; Rosa, M.P. Histopathologic features and management of ameloblastoma: Study of 20 cases. Sao Paulo Med. J./Rev. Paul. Med. 1999, 117, 171-174. [CrossRef]

2. Hong, J.; Yun, P.-Y.; Chung, I.-H.; Myoung, H.; Suh, J.-D.; Seo, B.-M.; Lee, J.-H.; Choung, P.-H. Long-term follow up on recurrence of 305 ameloblastoma cases. Int. J. Oral Maxillofac. Surg. 2007, 6, 283-288. [CrossRef]

3. Miloro, M.; Ghali, G.E.; Larsen, P.; Waite, P. Peterson's Principles of Oral and Maxillofacial Surgery, 3rd ed.; People's Medical Publishing House: Montpelier, VT, USA, 2012; Volume 1, pp. 3-4.

4. Pertovic, I.; Ahmed, Z.U.; Huryn, J.M.; Nelson, J.; Allen, R.J., Jr.; Matros, E.; Rosen, E.B. Oral rehabilitation for patients with marginal and segmental mandibulectomy: A retrospective review of 111 mandibular resection prostheses. J. Prosthet. Dent. 2019, 122, 82-87.

5. Lundgren, S.; Sjöström, M.; Nyström, E.; Sennerby, L. Strategies in reconstruction of the atrophic maxilla with autogenous bone grafts and endosseous implants. Periodontol 2000 2008, 47, 143-161. [CrossRef] [PubMed]

6. Misch, C.M. Bone augmentation using allogeneic Bone blocks with recombinant bone morphogenetic protein-2. Implant Dent. 2017, 26, 826-831. [CrossRef] [PubMed]

7. Hamer, A.J.; Strachan, J.R.; Black, M.M.; Ibbotson, C.J.; Stockley, I.; Elson, R.A. Biomechanical properties of cortical allograft bone using a new method of bone strength measurement: A comparison of fresh, fresh-frozen, and irradiated bone. J. Bone Jt. Surg. Br. 1996, 78, 363-368. [CrossRef] [PubMed]

8. McAllister, B.S.; Haghighat, K. A bone augment. Tech. J. Periodontol. 2007, 78, 377-396. [CrossRef] [PubMed]

9. Marx, R.E.; Shellenberger, T.; Wimsatt, J.; Correa, P. Severely resorbed mandible: Predictable reconstruction with soft tissue matrix expansion (tent pole) grafts. J. Maxillofac. Surg. 2002, 60, 878-888. [CrossRef] [PubMed]

10. Sham, E.; Leong, J.; Maher, R.; Schenberg, M.; Leung, M.; Mansour, A.K. Mandibular ameloblastoma: Clinical experience and literature review. ANZ J. Surg. 2009, 79, 739-744. [CrossRef]

11. Elnayef, B.; Monje, A.; Gargallo-Albiol, J.; Galindo-Moreno, P.; Wang, H.L.; Hernández-Alfaro, F. Vertical ridge augmentation in the atrophic mandible: A systematic review and meta-analysis. Int. J. Oral Maxillofac. Implants 2017, 32, 291-312. [CrossRef]

12. Pogrel, M.A.; Podlesh, S.; Anthony, J.P.; Alexander, J. A comparison of vascularized and nonvascularized bone grafts for reconstruction of mandibular continuity defects. J. Oral Maxillofac. Surg. 1997, 55, 1200-1206. [CrossRef]

13. Rachmiel, A.; Emodi, O.; Aizenbud, D.; Rachmiel, D.; Shilo, D. Two-stage reconstruction of the severely deficient alveolar ridge: bone graft followed by alveolar distraction osteogenesis. Int. J. Oral Maxillofac. Surg. 2018, 47, 117-124. [CrossRef]

14. Herford, A.S.; Boyne, P.J. Reconstruction of mandibular continuity defects with bone morphogenetic protein-2 (rhBMP-2). J. Oral Maxillofac. Surg. 2008, 66, 616-624. [CrossRef]

15. Hoffmann, A.; Gross, G. BMP signaling pathways in cartilage and bone formation. Crit. Rev. ${ }^{\mathrm{TM}}$ Eukaryot. Gene Expr. 2001, 11, 1-3. [CrossRef] 
16. Jäger, M.; Herten, M.; Fochtmann, U.; Fischer, J.; Heringou, P.; Zilkens, C.; Hendrich, C.; Krauspe, R. Bridging the gap: Bone marrow aspiration concentrate reduces autologous bone grafting in osseous defects. J. Orthop. 2011, 29, 173-180. [CrossRef] [PubMed]

17. Tatullo, M.; Falisi, G.; Amantea, M.; Rastelli, C.; Paduano, F.; Marrelli, M. Dental pulp stem cells and human periapical cyst mesenchymal stem cells in bone tissue regeneration: Comparison of basal and osteogenic differentiated gene expression of a newly discovered mesenchymal stem cell lineage. J. Biol. Regul. Homeost. 2015, 29, 713-718.

18. Tatullo, M.; Codispoti, B.; Pacifici, A.; Palmieri, F.; Marrelli, M.; Pacifici, L.; Paduano, F. Potential use of human periapical cyst-mesenchymal stem cells (hpcy-mscs) as a novel stem cell source for regenerative medicine applications. Front. Cell Dev. Biol. 2017, 5, 103. [CrossRef]

19. Uccelli, A.; Prockop, D.J. Why should mesenchymal stem cells (MSCs) cure autoimmune diseases? Curr. Opin. Immunol. 2010, 22, 768-774. [CrossRef] [PubMed]

20. Ballini, A.; Cantore, S.; Scacco, S.; Coletti, D.; Tatullo, M. Mesenchymal stem cells as promoters, enhancers, and playmakers of the translational regenerative medicine. Stem Cells Int. 2018, 1-2. [CrossRef]

21. Marrelli, M.; Maletta, C.; Inchingolo, F.; Alfano, M.; Tatullo, M. Three-point bending tests of zirconia core/veneer ceramics for dental restorations. Int. J. Dent. 2013, 1-5. [CrossRef]

22. Nørholt, S.E.; Jensen, J.; Schou, S.; Pedersen, T.K. Complications after mandibular distraction osteogenesis: A retrospective study of 131 patients. Oral Surg. Oral Med. Oral Pathol. Oral Radiol. End. 2011, 111, 420-427. [CrossRef] [PubMed]

23. Isola, G.; Alibrandi, A.; Rapisarda, E.; Matarese, G.; Williams, R.C.; Leonardi, R. Association of vitamin D in patients with periodontal and cardiovascular disease: A cross-sectional study. J. Periodontal Res. 2020. [CrossRef] [PubMed]

24. Isola, G.; Polizzi, A.; Santonocito, S.; Alibrandi, A.; Ferlito, S. Expression of salivary and serum malondialdehyde and lipid profile of patients with periodontitis and coronary heart disease. Int. J. Mol. Sci. 2019, $20,6061$. [CrossRef] [PubMed]

25. Chen, Y.C.; Ninomiya, T.; Hosoya, A.; Hiraga, T.; Miyazawa, H.; Nakamura, H. 1 1 ,25-Dihydroxyvitamin D3 inhibits osteoblastic differentiation of mouse periodontal fibroblasts. Arch Oral Biol. 2012, 57, 453-459. [CrossRef] [PubMed]

26. Mahajan, A. Periosteum: A highly underrated tool in dentistry. Int. J. Dent. 2012. [CrossRef] [PubMed]

27. Roh, J.L. Removal of the submandibular gland by a submental approach: A prospective, randomized, controlled study. Oral Oncol. 2008, 44, 295-300. [CrossRef] 